Tajdaran, S, Bonatesta, F, Ogden, R and Kendrick, C

CFD modeling of transpired solar collectors and characterisation of multi-scale airflow and heat transfer mechanisms.

Tajdaran, S, Bonatesta, F, Ogden, R and Kendrick, C (2016) CFD modeling of transpired solar collectors and characterisation of multi-scale airflow and heat transfer mechanisms. Solar Energy, 131 (). pp. 149-164.

doi: 10.1016/j.solener.2016.02.042

This version is available: https://radar.brookes.ac.uk/radar/items/59483611-3803-4af6-80ae-3b126c794733/1/

Available on RADAR: March 2017

Copyright $@$ and Moral Rights are retained by the author(s) and/ or other copyright owners. A copy can be downloaded for personal non-commercial research or study, without prior permission or charge. This item cannot be reproduced or quoted extensively from without first obtaining permission in writing from the copyright holder(s). The content must not be changed in any way or sold commercially in any format or medium without the formal permission of the copyright holders.

This document is the post print version of the journal article. Some differences between the published version and this version may remain and you are advised to consult the published version if you wish to cite from it. 


\title{
CFD modeling of transpired solar collectors and characterisation of multi-scale airflow and heat transfer mechanisms
}

\author{
Sadjad Tajdaran $^{\mathrm{a}^{*}}$, Fabrizio Bonatesta ${ }^{\mathrm{a}}$, Raymond Ogden ${ }^{\mathrm{a}}$ Christopher Kendrick $^{\mathrm{a}}$ \\ ${ }^{a}$ Oxford Brookes University, Gipsy Lane, Oxford OX3 OBP, UK
}

\begin{abstract}
Transpired Solar Collectors (TSCs) are building-integrated air-heating systems that are able to fully or partially meet the heating demands of buildings. They convert solar radiation into warm air that can either be used for ventilation, or to heat thermal storage media. TSCs are becoming an increasingly viable alternative to conventional fossil fuel-based heating systems or, more commonly, can be used in a way that is complementary to these systems such that reliance on fossil fuels is reduced. As a consequence TSCs have a potentially important role in meeting future carbon reduction goals.
\end{abstract}

This research has produced a comprehensive numerical model for TSCs based on Computational Fluid Dynamic (CFD) analyses. The model allows parametric studies of key variables and is differentiated from previous models in that it takes full account of factors such as: wind speed and direction, non-uniform flow, turbulent flow, solar radiation intensity, sun position and flow suction rates. It comprises a full size section of cassette-panel TSC that can be easily morphed to reflect a wide range of geometries. A multi-block meshing approach has been employed to reduce grid size and to also resolve jet flows and boundary layers taking place in the plenum and around the absorber plate. Accuracy of the CFD model has been validated against experimental data.

Modeling demonstrated that factors such as wind angle have unexpectedly significant adverse effects on system thermal performance. The studies also furthered understanding of key performance attributes including the effects of suction ratio in terms of optimising performance, and the relationship between sun angle and system operating temperature (important for effective operation of heat storage systems). Consideration of these factors is essential if the future performance of TSCs is to be optimised and the technology developed to its fullest potential.

Keywords: Transpired solar collectors; Computational Fluid Dynamics; Heat Transfer

\section{Introduction}

In support of $2050 \mathrm{EU}$ carbon reduction targets, the UK is committed to reduce emissions by $80 \%$ in comparison with 1990 levels (Commission of the European Communities, 2014). Buildings are responsible for approximately $40 \%$ of energy consumption and $37 \%$ of greenhouse gas emissions, with a large proportion of energy use associated with heating (Committee on Climate Change, 2014). Heating energy reduction in buildings is therefore crucial to achieving this target.

Reducing reliance on fossil fuels will require the further development of viable and effective low carbon energy generation techniques. The range of approaches is however somewhat limited comprising primarily solar solutions (solar collectors and photovoltaics) and wind and wave approaches. Relatively little consideration has thus far been extended to Transpired Solar Collectors (TSCs) which are potentially highly cost effective solutions in relation to heat demand (Kutscher, 1992; Arulanandam et al, 1999; Li et al, 2014)

TSCs were originally developed in Canada for summer crop-drying, but as a consequence of design optimisation can now be used to supplement building space heating in temperate climates by providing useful amounts of warm air in the Autumn and Spring (Hollick, 1994). TSCs are typically able to deliver air $10-15^{\circ} \mathrm{C}$ warmer than ambient external temperature (Hall et al. 2013). This warm air can either be ducted directly into buildings or be used as preheat for 'Heating, Ventilation and Air Conditioning' (HVAC) systems (Athienitis et

\footnotetext{
Corresponding author. Tel.:+44-1865-484086.

E-mail address: stajdaran@brookes.ac.uk
} 
al., 2011).

\begin{tabular}{|c|c|}
\hline \multicolumn{2}{|c|}{ Nomenclature } \\
\hline$C_{p}$ & specific heat capacity, $1.005 \mathrm{~kJ} / \mathrm{kg} \mathrm{K}$ \\
\hline G & solar radiation falling on the TSC plate per unit area, $\mathrm{W} / \mathrm{m}^{2}$ \\
\hline$Q_{c . i n}$ & convective heat gain, $\mathrm{W} / \mathrm{m}^{2}$ \\
\hline$Q_{\text {c.out }}$ & convective heat loss, $\mathrm{W} / \mathrm{m}^{2}$ \\
\hline$Q_{\text {gain }}$ & heat obtained by the TSC system, $\mathrm{W} / \mathrm{m}^{2}$ \\
\hline$Q_{\text {r.in }}$ & radiative heat loss, $\mathrm{W} / \mathrm{m}^{2}$ \\
\hline$Q_{\text {r.out }}$ & radiative heat loss, $\mathrm{W} / \mathrm{m}^{2}$ \\
\hline$T_{a m b}$ & free stream ambient air temperature \\
\hline$T_{\text {out }}$ & outlet air temperature \\
\hline$T_{s}$ & absorber surface temperature \\
\hline$U_{\infty}$ & free stream wind velocity \\
\hline$V_{s}$ & mean suction velocity \\
\hline$y^{+}$ & dimensionless wall distance \\
\hline \multicolumn{2}{|c|}{ Greek symbols } \\
\hline$\beta$ & wind angle \\
\hline$\varepsilon$ & heat exchange effectiveness \\
\hline$\eta$ & thermal efficiency of the TSC system \\
\hline \multicolumn{2}{|c|}{ Abbreviation } \\
\hline CFD & Computational Fluid Dynamics \\
\hline HEE & Heat Exchange Effectiveness \\
\hline RANS & Reynolds-Averaged Navier Stokes \\
\hline SIMPLE & Semi-Implicit Method for Pressure-Linked Equations \\
\hline
\end{tabular}

Transpired Solar Collectors are wall-mounted air heating systems comprising a perforated steel sheet installed on a building façade that acts as a solar absorber (Fig 1). The perforated plate absorbs solar radiation from the sun and heats air local to its surfaces and that passes through the perforations. A fan sucks air into a plenum behind the absorber plate through the perforations, and in simple arrangements delivers the warmer air into the interior of the building where there is heating demand. Heat transfer takes place continuously as the air travels through the absorber plate and into the plenum, being concentrated mostly at the air-steel interface and at the perforations. The heated air is used to wholly or partially satisfy ventilation requirements. Of the solar radiation falling onto the absorber $(G)$, a portion is gained by the system $\left(Q_{\text {gain }}\right)$; the remainder is accounted for by system radiative and convective heat losses $\left(Q_{\text {loss }}\right)$. The system thermal efficiency is defined as:

$\eta=\frac{\left(Q_{\text {gain }}\right)}{G}=\frac{\rho V_{s} C_{p}\left(T_{\text {out }}-T_{\text {amb }}\right)}{G}$

In spite of the apparent simplicity of the approach, the thermodynamic and fluid-dynamic characterisation of TSCs is complex. A variable turbulent external flow approaches the absorber surface, and a boundary layer forms over the plate, governing heat and airflow transfers. The pressure drop across the perforated plate induces suction of air through perforations with the consequent formation of jet flows within the plenum. All types of heat transfer establish at the same time, including convection on both sides of the perforated plate, conduction through the steel plate and radiation. The multi-scale geometrical nature of the system inherently complicates the way these processes affect system thermal response and efficiency.

An advanced understanding of these mechanisms and of how external climate conditions modify them is essential for system optimisation. Whilst experimental analysis of TSC systems will be an essential component of future systems development it is costly and time consuming, and needs to be informed by robust analytical predictions. Numerical models, and in particular three-dimensional CFD models, are flexible and once appropriately validated, provide a reliable, inexpensive platform to explore the effects of design modifications and variable operating conditions. A principle aim of this study has been to develop a comprehensive CFD model for TSC systems that considers all relevant physical mechanisms described at correct physical scales, that can be used reliably for system analysis and optimisation. 


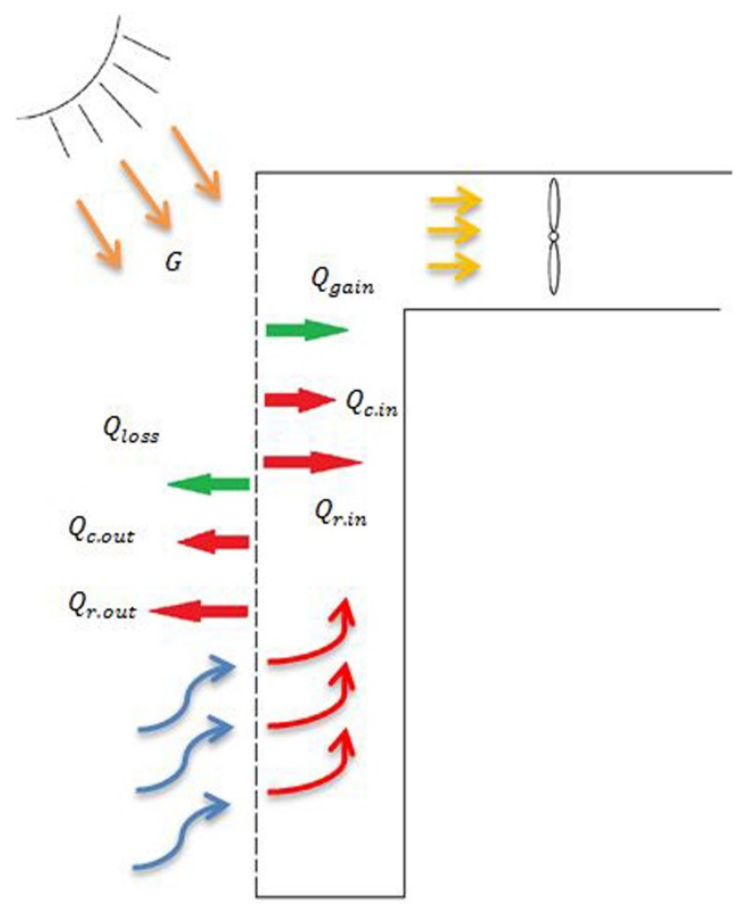

Fig 1. Schematic diagram of the thermal field in TSCs

\subsection{Background}

For a given system geometry and incident solar energy, the suction velocity $\left(V_{s}\right)$ and the velocity of the external approaching flow (i.e. wind speed, $U_{\infty}$ ) are key variables determining the performance of systems (Kutscher, 1994, Biona et al., 2005). The suction process in TSCs is mainly driven by fan power. The pressure gradient in the plenum causes air to flow through the perforations and towards the exit arrangement at the top of the plenum. Pressure distribution across the absorber plate and the plenum are dependent on the location of the fan (Dymond and Kutscher, 1997; Gawlik et al. 2005). Non-uniformities in the airflow in the plenum are also induced by buoyancy as a result of the temperature gradient generated on the absorber's surface by solar radiation. Gunnewiek et al. (1996) have observed that within the plenum airflow is fundamentally non-uniform due to the continuous interaction between buoyancy force and fan drag force. Importantly, the heated air passing through discrete perforations produces characteristic jet flows every few centimetres across the plate depending on pitch distance. These jets interact with the bulk airflow travelling upwards creating turbulence and further non-uniformity. The assumption of uniform plenum flow found in some literature (Kutscher, 1992; Arulanandam et al., 1999) may undermine the reliability of system analysis and results. A full, realistic description of the flow within the plenum and of the jets interaction can be achieved with accurate threedimensional CFD modelling of a full-scale system and with the provision of a multi-scale, locally refined, computational mesh.

A great deal of interaction takes place between the absorber plate surface and the fluid flow moving over it, within the thin layer of fluid in the immediate vicinity of the solid-fluid interface. The establishment of a boundary layer region influences both the thermodynamic, and the fluid mechanic mechanisms that occur and has a strong effect on system performance. The evaluation of the solid-fluid heat transfer would be inaccurate without appropriate information on the flow characteristics in the boundary layer region. Based on Schlichtings's homogenous suction theory (Schlichting, 1979), the rate of suction through the perforations determines the transition from turbulent to laminar flow. A boundary layer may establish over the perforated plate after a specific starting length, and the suction velocity determines whether the layer thickness remains constant (asymptotic boundary layer). The asymptotic region can be either laminar or turbulent, depending on suction rate, surface porosity and the upstream flow type (Dutton, 1958). The minimum suction velocity to support an asymptotic boundary layer has been given as $V_{S}=1.24 \times 10^{-4} U_{\infty}$ (Schlichting, 1979). The ratio of the suction velocity to wind speed $\left(V_{s} / U_{\infty}\right)$ has also been recognised as a determining variability in the development of boundary layers (Dutton, 1958; Moffat and Kays, 1984). Higher wind speeds require higher suction velocity to avoid reverse flow over the perforated plate. Moffat and Kays (1984) found that a suction ratio in excess of 0.004 determines the transition between turbulent boundary layers and asymptotic laminar boundary layers. Gunnewiek et al. (2002) studied two different types of building with constant wind speed of 5 
$\mathrm{m} / \mathrm{s}$. They found that the minimum suction velocity required to avoid reverse flow was $0.017 \mathrm{~m} / \mathrm{s}$ for long buildings and $0.026 \mathrm{~m} / \mathrm{s}$ for cubical buildings, respectively. For a given wind speed, higher suction velocity implies higher suction ratio, which in turn results in lower system operating temperature (Biona et al. 2005; Leon and Kumar,2007).

By applying Schlichtings's hypothesis of homogeneous suction, Kutcher (1992) developed an empirical model for the evaluation of heat loss of flat TSC systems. According to this theory, an asymptotic boundary layer develops when there is no energy and momentum transfer into the boundary layer and the heat loss by natural convection is considered negligible after the starting length (Kutscher et al., 1993; Abulkhair and Collins, 2010). This approach may reduce the complexities of TSC modelling, however it would not be able to capture the nature of real applications where suction is non-homogenous and the external flow is neither laminar nor uniform (Li et al., 2013). By referring to the same homogenous flow theory, some experimental studies (Golneshan, 1994; Van Decker, 2001) assumed repeating flow behaviour over the perforated place. Whilst this meant that the size of the test system could be was therefore less than $0.5 \mathrm{~m}^{2}$, and larger potentially more realistic physical systems were not investigated.

Effective analysis of systems requires suitable computational resources and three-dimensional modelling techniques (Tajdaran et al., 2015) and is complex. For this reason, a range of simplifications concerning the underlying physics, as well as system size, geometry and boundary conditions, are routinely adopted. For example, some models assume periodic behaviour of the flow over the absorber plate and include only one perforation for flat plates or one corrugation for profiled plates (Arulanandam et al., 1999; Gawlik and Kutscher, 2005; Collins and Abulkhair, 2014). Conversely, Li et al. $(2013,2014)$ investigated flow and heat transfer for a full scale experimental apparatus using three-dimensional CFD models, which were validated with test data. Heat transfer by radiation was excluded from the study and the approaching flow was set to be parallel to the absorber plate.

The research described in the following sections is based on three-dimensional full-scale CFD modelling to investigate flow and thermal behaviour in the context of cassette-panel transpired solar collectors (Fig. 2). The models are based on the geometry of a prototype system installed on the south-faced façade of a disused residential building at Oxford Brookes University (latitude $51.75^{\circ}$, longitude $-1.13^{\circ}$ ). This trial site is one of the few large scale experimental facilities where TSCs have been studied in the necessary level of detail (Fig. 3).

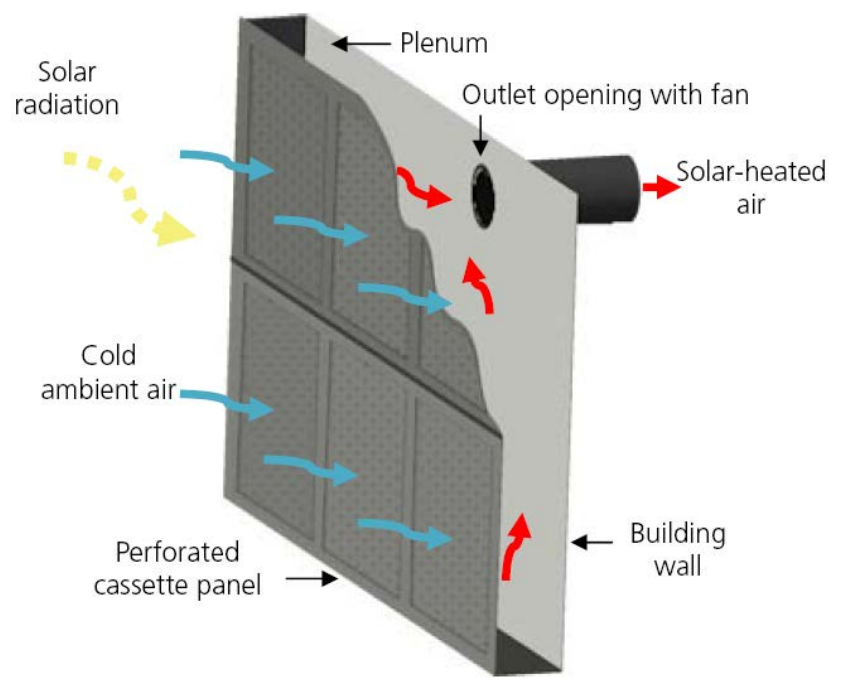

Fig. 2. Conceptual illustration of a CP-TSC solar air-heating system

Two cassette-panel TSCs were tested on the building; one system was trialled with an insulation board attached to the façade to reduce fabric thermal storage effects (first floor) whilst the second system was installed directly over the existing building façade (precast concrete panels) to allow fabric thermal storage to be fully effective(second floor). Environmental conditions were monitored using a weather station that recorded wind speed and direction, air temperature, solar radiation and humidity. Air temperature was also recorded in the plenum, outlet duct and in the rooms served by the system. The system was monitored continuously over a period of 88 days. The measured data showed that both systems are able to raise the air temperature by 10$15^{\circ} \mathrm{C}$. It was also noted that the temperature of the insulation layer stayed almost constant whereas the concrete wall heated by a few degrees during the day and largely transferred this heat back to the plenum air at night. 


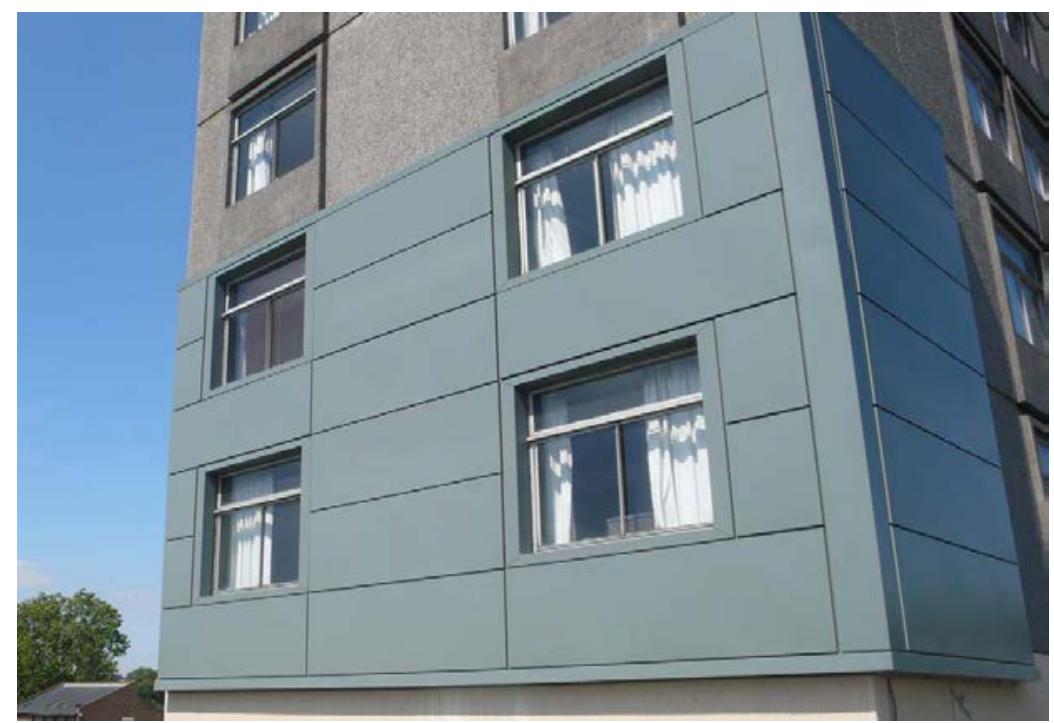

Fig. 3. Building façade with the installed cassette-panels (the perforated panels are the four panels directly between the windows)

Experimental data acquired using this system was used to validation purposes. The model encompasses a full-scale section of the prototype system and uses advanced meshing techniques to minimise the computational cost. The model considered the full range of underpinning physics and a 'Solar Load' sub-model to simulate solar radiation over the absorber plate. The model is believed to provide the most accurate performance representation of TSCs hitherto available being able to properly reflect key variables including airflow (notably wind speed and wind angle), solar radiation intensity (based sun position), turbulent flow across the system, and non-uniform flow suction through perforated plates. It is able to consider the effect of these variables in isolation, and assessment of their relative importance. The influence of suction ratio in combination with climate conditions has also been investigated.

The aim of the present work has been to improve the current understanding of the underlying physics of TSC systems; and at the same time, to provide the details of a suitably accurate modeling approach for system optimisation. TSC optimisation is essential both to extend the periods of useful operation and to produce higher grade heat for thermal storage

\section{Methodology}

\subsection{Numerical approach and grid design}

The commercial CFD software STAR-CCM+ has been used to solve steady-state, three-dimensional Reynolds Averaged Navier-Stokes (RANS) equations with the Realizable $k-\varepsilon$ turbulence closure model over the computational domain. A segregated flow solver has been adopted to solve flow equations using a second order upwind discretization scheme along with SIMPLE algorithm for pressure-velocity coupling. The simulations included all modes of heat transfer with specified values of emissivity, absorptivity and thermal conductivity on all relevant surfaces. Sun position was set as a function of the local time zone using the Solar Load sub-model; actual measured values of solar radiation intensity were used as the boundary condition (Hall et al., 2013). Simulation convergence was determined via the simulation residuals, but also by monitoring maximum velocity and pressure within critical locations of the flow field, and average and maximum temperature and heat transfer coefficient over the interface between plate and ambient air.

The existence of very small circular perforations (diameter $1.5 \times 10^{-3} \mathrm{~m}$ ) over a relatively large surface area $(2.73 \mathrm{~m} \times 1.74 \mathrm{~m})$ resulted in a multi-scale geometry. In order to capture the relevant airflow behaviour, the boundary layer and the jets emerging from the perforations into the plenum, a multi-scale, locally-refined, multi-block, adaptive, hexahedral mesh grid was generated using the 'Conformal Trimmer' meshing approach (STAR-CCM+ user guide, 2014). The typical cell size was of the order of $0.2 \mathrm{~mm}$ around the perforations and $10 \mathrm{~mm}$ away from the absorber plate (Fig. 4a). The characteristics of the jet flows were captured by creating refined conical grid regions adjacent to each single perforation, as shown in Fig. $4 \mathrm{~b}$. Specific mesh tests showed that a cone penetration of $20 \mathrm{~mm}$ was sufficient to give the jet flow independence from the mesh size. The final computational domain included $11 \mathrm{M}$ cells in total. The simulations have been executed using the High Performance Computing Cluster available at Oxford Brookes University. The flow in the region adjacent to the 
walls was resolved using 'Two-Layer All y+ Wall Treatment' wall function (STAR-CCM+ user guide, 2014). Mesh design and generation in that region was carried out in a way to maintain the $y+$ level of the first cell layer (the viscous sub-layer) to less than 5 .

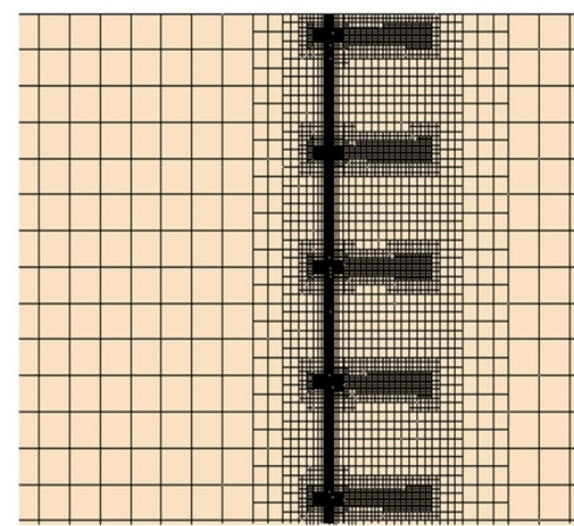

a)

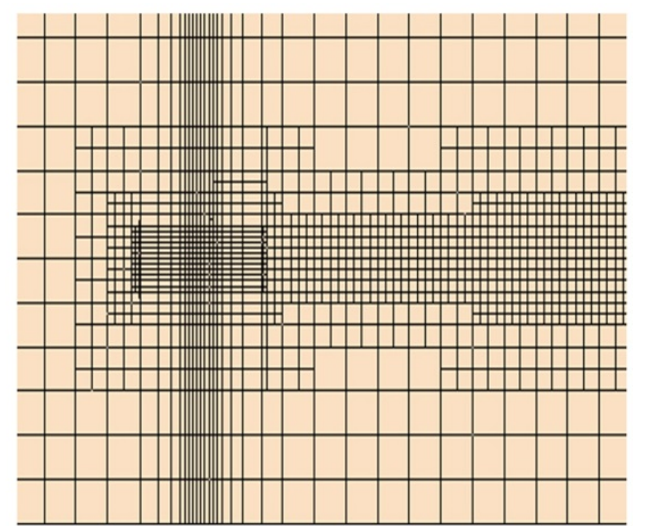

b)

Fig. 4. Hexahedral Mesh created around the plate and in the free-stream region; b) Details of the conical grid scheme to capture the jet flow

\subsection{Boundary conditions}

The CFD model is based on a prototype cassette-panel TSC and comprises a full-size vertical section of the system with circular perforations (pitch $20 \mathrm{~mm}$ ) in the absorber plate. This configuration of the computational domain enabled capture of the local pressure gradient in the vertical direction, arising from the fan. The pressure gradient was not considered significant in the stream wise direction in the fully developed region over the plate so extended surfaces were created either side of the perforated plate to ensure boundary layer growth over the perforated plate in the horizontal direction. The model geometry and associated boundary conditions are given in Fig. 5.

The approaching external flow (wind) has been simulated using a 'velocity inlet' boundary condition at the left and front sides of the ambient region, with a specified wind angle $(\beta)$, wind speed $\left(U_{\infty}\right)$ and a typical value of $1 \%$ for turbulence intensity. The right side of the domain was set as 'pressure outlet' using a zero gauge pressure condition. The absorber plate was defined as a solid region with specified values of absorptivity, emissivity and conductivity. The plenum region has been modelled in its full size, facilitating the simulation of a realistic bulk flow stream. The top side of the plenum was defined as 'mass flow inlet' with a negative value of mass flow rate of air to represent the fan drawing air through the perforations and into the building. Adiabatic wall of specified emissivity was set for the rear and bottom side of the plenum domain and 'symmetry' boundary condition was set for the left and right sides. 


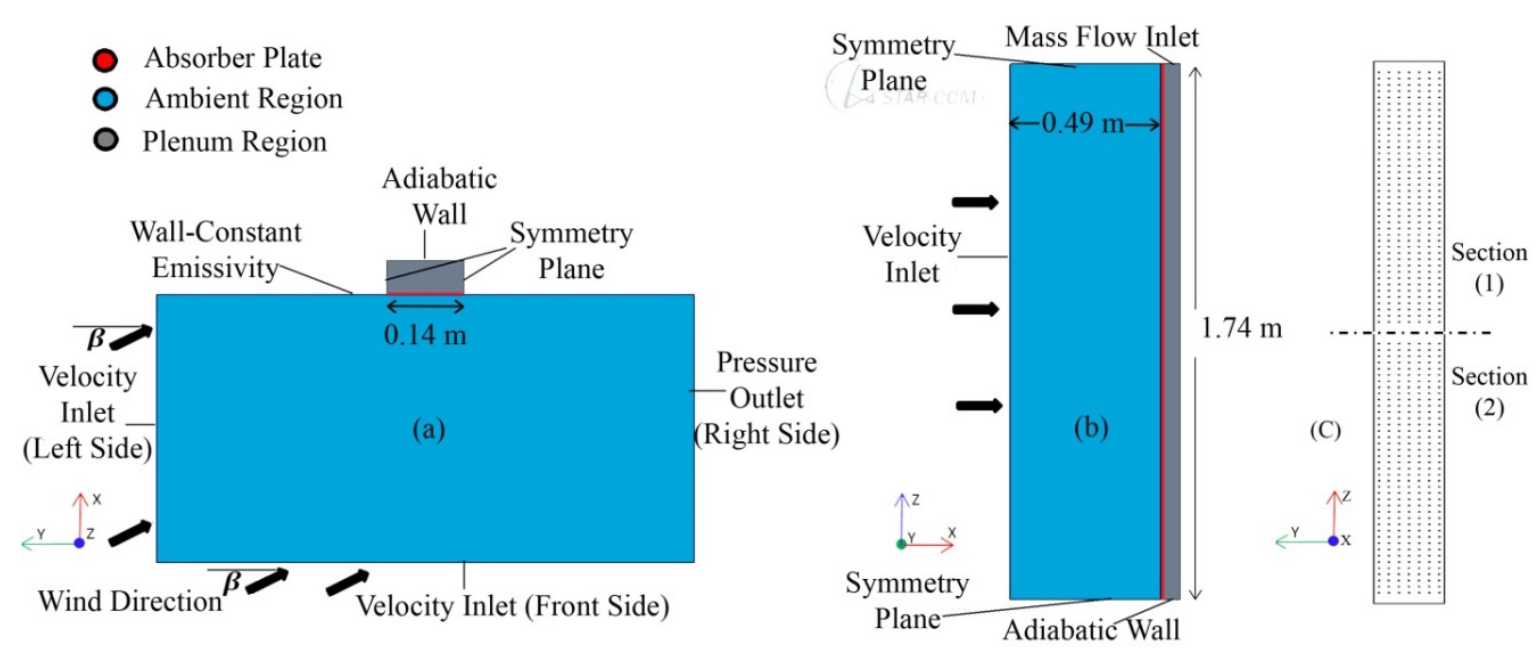

Fig. 5. Computational domain and model configuration; (a) Top view, (b) Side view, (c) Sketch of the absorber plate.

\subsection{Model Validation}

A two-fold model validation process has been carried out based on available experimental data (Hall et al., 2013). Comparisons were drawn between modelled and measured values of absorber plate temperature $\left(T_{s}\right)$, as well as between modelled and measured values of plenum outlet temperature $\left(T_{\text {out }}\right)$. The plate temperature was calculated as the average of several locations on the inner side of the plate and it is taken as representative of the interaction between internal and external flows in steady-state conditions. The plenum outlet temperature was taken at the top of the plenum, with the insulated building façade (Hall et al., 2013). This second validation criterion was thought to be essential as it represents the quality of the air delivered into the building. A set of 15 operating conditions covering a wide range of climate variables has been used to assess the CFD model accuracy and reliability. These are summarised in Table 1.

Table 1. Details of the cases used for validation.

\begin{tabular}{|c|c|c|c|c|c|}
\hline $\begin{array}{c}\text { Case } \\
\text { Number }\end{array}$ & $\begin{array}{c}\text { Ambient Air } \\
\text { Temperature }\left({ }^{\circ} \mathrm{C}\right)\end{array}$ & $\begin{array}{l}\text { Wind Speed }(\boldsymbol{m} / \boldsymbol{s}) \\
\boldsymbol{U}_{\infty}\end{array}$ & $\begin{array}{c}\text { Wind Angle }\left(^{\circ}\right) \\
\boldsymbol{\beta}\end{array}$ & $\begin{array}{c}\text { Suction Ratio } \\
\boldsymbol{V}_{\boldsymbol{s}} / \boldsymbol{U}_{\infty}\end{array}$ & $\begin{array}{l}\text { Vertical Solar Radiation } \\
\qquad\left(\boldsymbol{w} / \boldsymbol{m}^{\mathbf{2}}\right)\end{array}$ \\
\hline 1 & 4.33 & 2.77 & 24.67 & 0.0087 & 425.09 \\
\hline 2 & 5.13 & 2.83 & 37.67 & 0.0086 & 585.99 \\
\hline 3 & 6.27 & 5.60 & 12.33 & 0.0044 & 646.90 \\
\hline 4 & 7.33 & 2.80 & 12.33 & 0.0089 & 277.80 \\
\hline 5 & 8.40 & 4.97 & -1.33 & 0.0049 & 570.08 \\
\hline 6 & 9.27 & 6.90 & 4.67 & 0.0034 & 101.04 \\
\hline 7 & 10.57 & 3.63 & 14.33 & 0.0067 & 621.92 \\
\hline 8 & 10.70 & 4.50 & 2.33 & 0.0036 & 629.64 \\
\hline 9 & 11.00 & 5.47 & 7.67 & 0.0030 & 767.11 \\
\hline 10 & 11.53 & 3.60 & -0.33 & 0.0069 & 735.64 \\
\hline 11 & 11.80 & 3.70 & 8.33 & 0.0067 & 724.31 \\
\hline 12 & 12.00 & 3.00 & 6.67 & 0.0083 & 705.82 \\
\hline 13 & 12.07 & 3.43 & 13.00 & 0.0073 & 577.79 \\
\hline 14 & 12.10 & 3.23 & 1.33 & 0.0076 & 546.72 \\
\hline 15 & 12.13 & 2.90 & 1.67 & 0.0086 & 615.50 \\
\hline
\end{tabular}

Fig. 6 shows the comparison between modelled and experimental data. 95\% of the cases are predicted with accuracy within $10 \%$, with $55 \%$ of the temperatures predicted within $5 \%$ of the experimental value. Considering that the experimental measurements themselves carry a degree of error due to life-like test conditions, the validation exercise implies that the sophisticated CFD model developed for this work is able to deliver an accurate and realistic representation of the performance of a TSC system. Importantly, the variety of validation 
cases suggests that the CFD model is flexible in nature and well suited to capture the influence of different climatic conditions, which is essential for design optimisation.

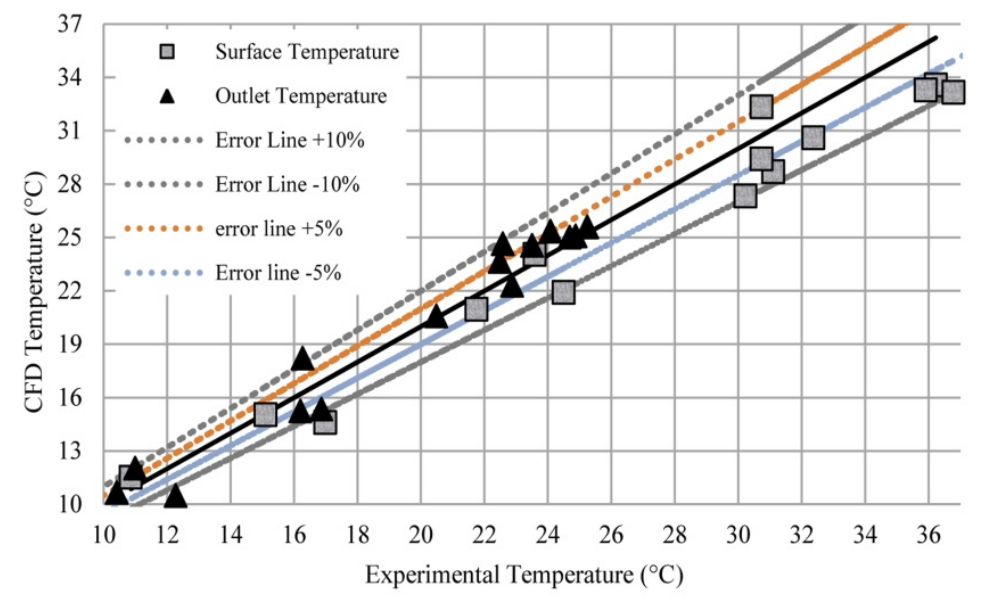

Fig. 6. Comparison between the CFD results and the experimental data for absorber surface and plenum outlet temperature.

\section{Results and discussion}

This section presents the airflow and thermal field analysis for one representative case, and parametric studies that investigate relevant climate variables. The flow field analysis uses post-processed CFD images to provide a visual insight as to how the TSC system works i.e. the airflow approaching the absorber plate, the processes of heat exchange, and the airflow within the plenum towards the system outlet. Studies consider the effect that variables including: solar radiation intensity and direction (i.e. time of day), suction ratio, and approaching flow conditions, have on system performance.

\subsection{Airflow and thermal field}

Fig. 7a shows the velocity streamlines and vectors in the computational domain for one representative case. It can be seen that wind with a specific angle approaches the absorber and exits the domain on the right hand side. Whilst the airflow enters the domain at a certain angle in the far field regions, it rather quickly takes a more parallel direction to the plate as it streams closer to the TSC's external surface. While this configuration may be different for wind speeds in excess of $6 \mathrm{~m} / \mathrm{s}$, and for a TSC panel located in the corner of a building, the results suggest that generally wind angle exerts only a limited influence on the thermal performance of TSC systems. The results can inform experimental work, especially in terms of where best to place weather stations in relation to flow streams around the absorber plates. Fig. $7 \mathrm{~b}$ displays the formation of jets in the plenum due to the suction through perforations, and the airflow in the far field. Notably, from a very high speed of 8 to $10 \mathrm{~m} / \mathrm{s}$, the jets quickly dissipate into the core flow travelling up at relatively low velocity $(0.5$ to $1.5 \mathrm{~m} / \mathrm{s})$. 


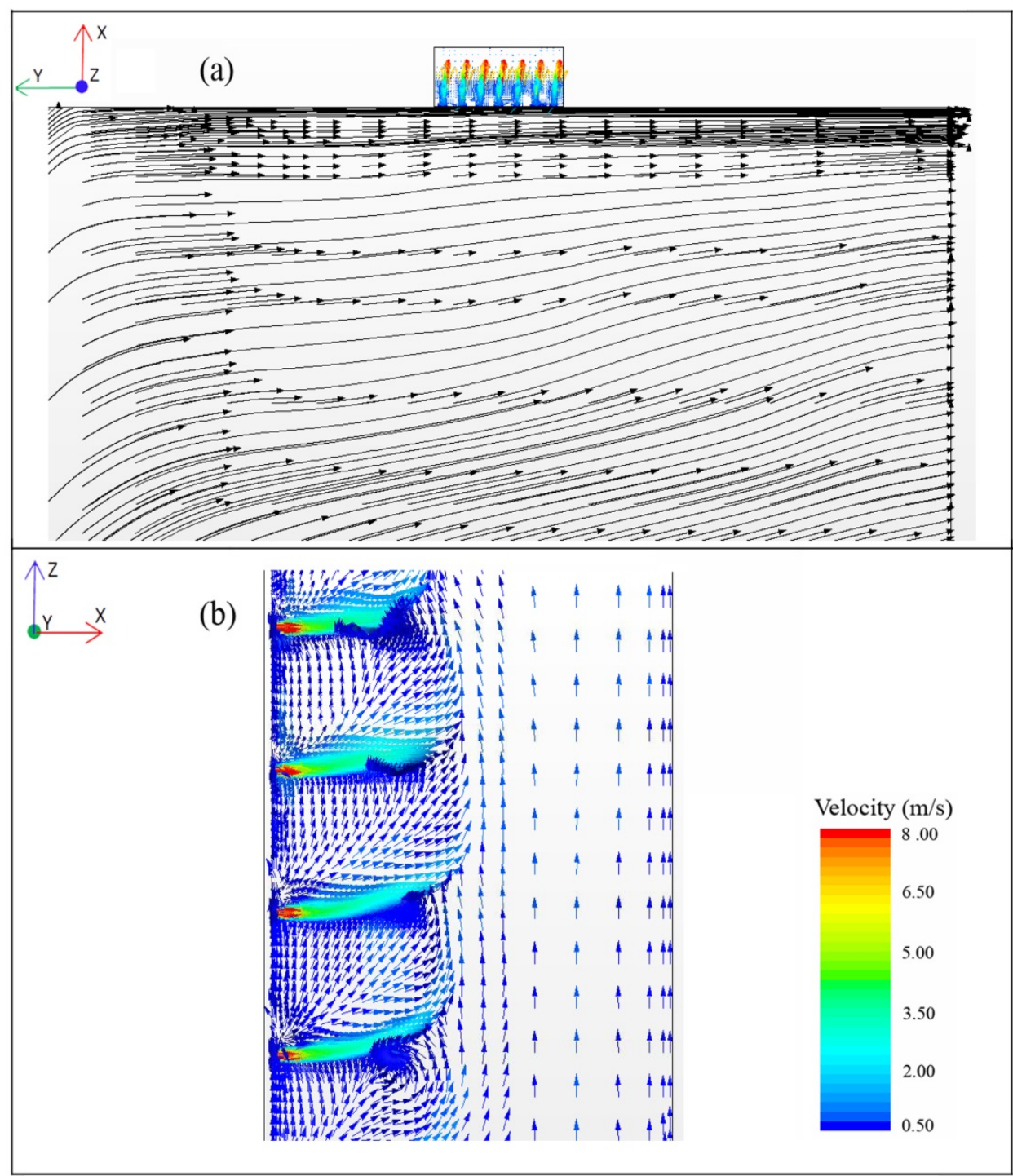

Fig. 7.(a) Velocity streamlines of ambient/external flow (view from above); (b) Airflow within the plenum (side view).

Due to the suction generated by the fan, the airflow experiences different velocity and pressure as it transfers across the system. As shown in Fig. 8, the pressure grows negatively moving upwards and, correspondingly, the bulk velocity within the plenum increases (Fig. 9). Solar radiation falls on the absorber plate and the system gains heat by sucking the heated air layer flowing over the plate. Fig. 10a shows the temperature distribution over the absorber plate. For increased clarity of visualisation, the regions with temperatures above $23^{\circ} \mathrm{C}$ are displayed in red and a similar approach is used in other figures throughout this section. A higher level of negative pressure and airflow velocity in the upper part of the plenum (section 1) cause this part to be relatively cooler especially at the very top, where the highest negative pressure is generated. Interestingly, a slightly greater temperature is seen all around the edge of the modelled TSC element, indicating the establishment of an 'edge effect' influencing the thermal performance of the system. Whilst the importance of the edge effect reduces with increasing front surface (i.e. in full-scale applications), the CFD environment enables exploration in detail as to how different parts of the absorber plate contribute to the level of outlet temperature $\left(T_{o}\right)$ and to the corresponding 'Heat Exchange Effectiveness' .

Heat Exchange Effectiveness $(\varepsilon)$ is defined as the actual heat transferred to the air, relative to the maximum theoretical heat transfer. Its definition is typically given in terms of ambient temperature $\left(T_{a m b}\right)$, outlet temperature $\left(T_{\text {out }}\right)$ and absorber surface temperature $\left(T_{s}\right)$ :

$$
\varepsilon=\frac{\left(T_{\text {out }}-T_{a m b}\right)}{\left(T_{s}-T_{a m b}\right)}
$$


As can be observed from the Eq. 2, for a given outlet temperature, greater surface temperature leads to smaller effectiveness. In other words, the regions of the absorber plate that operate at higher temperature, contribute less to the final air temperature delivered by the system. Fig. 10b shows the distribution of HEE over the absorber plate. Heat transfer is clearly maximised around the top region with levels of HEE $\geq 1$, indicating that the surface temperature is either equal or less than the outlet temperature. Magnified side views of temperature and velocity distribution in the upper part of plenum are presented in Fig. 11. While the absence of perforations in the uppermost region leads to higher surface temperature and lower HEE, the increased heat transfer across the first few perforated rows leads to a localised area of lower temperature and greater HEE.

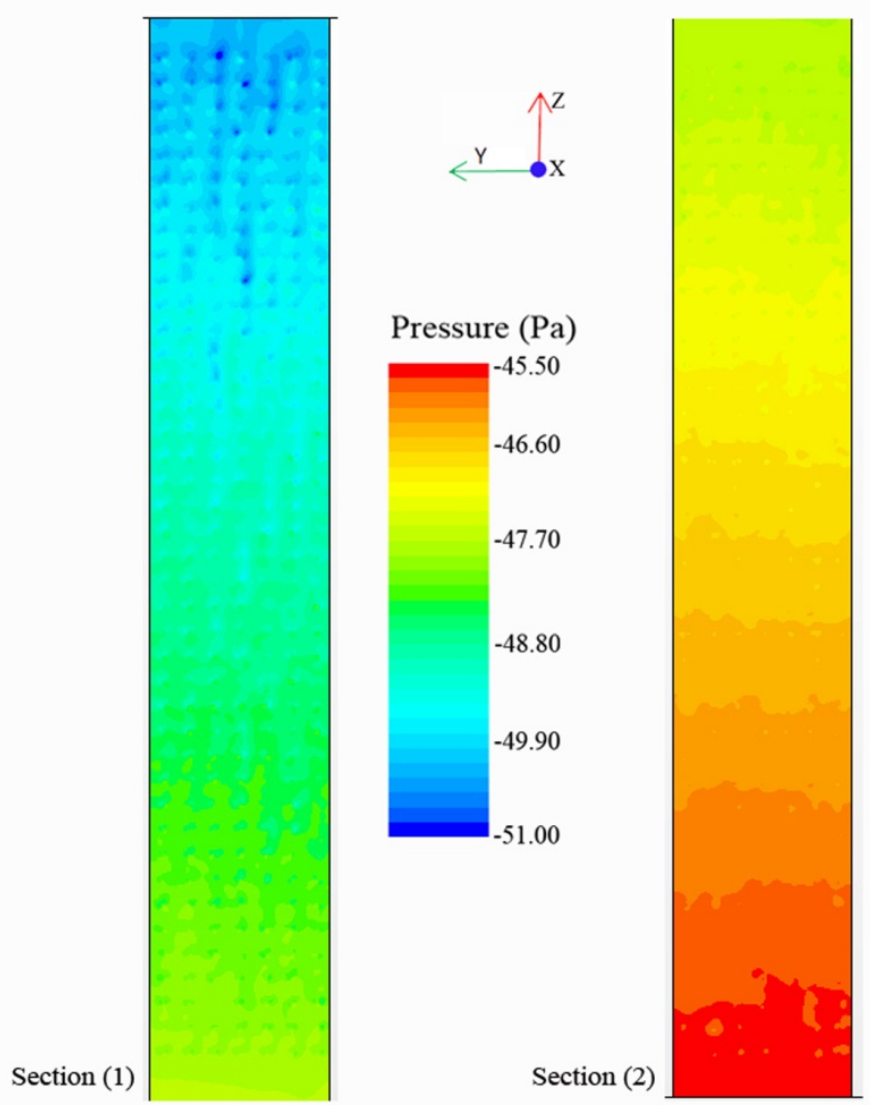

Fig. 8. Front view of pressure distribution on centre-line of plenum; Section (1): upper part of plenum, Section (2): lower part of plenum. 


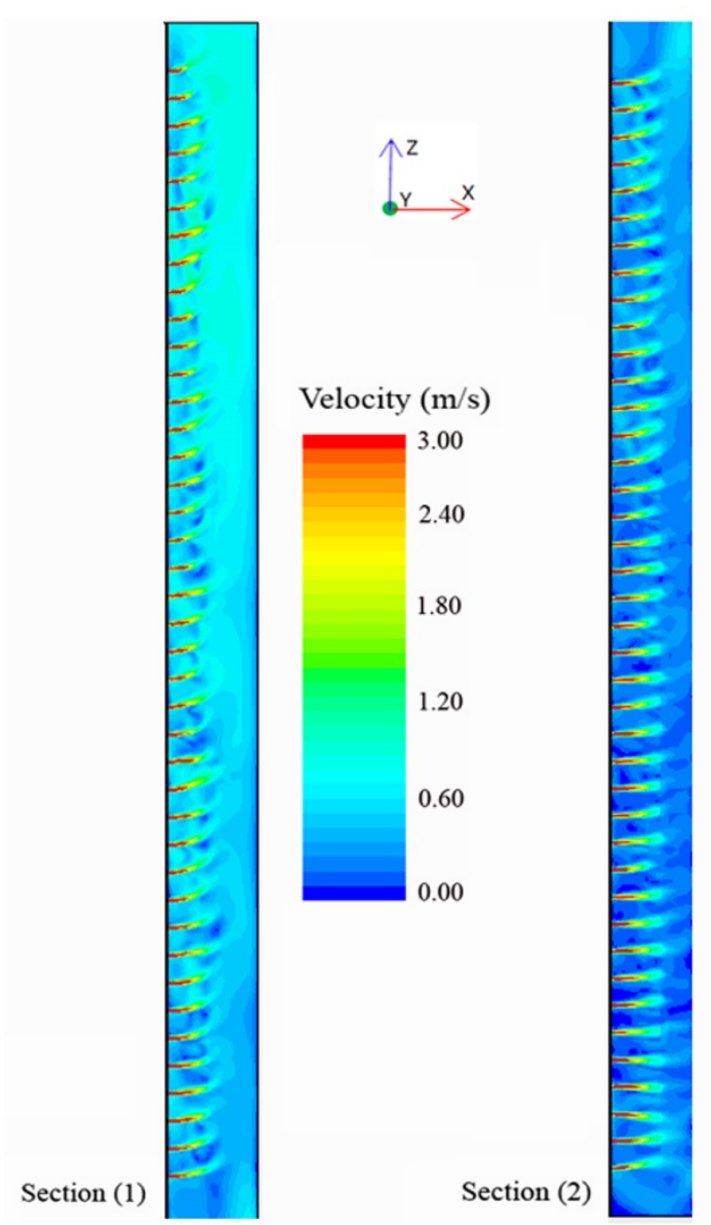

Fig. 9. Cross section of plenum showing velocity distribution; Section (1): upper part of plenum, Section (2): lower part of plenum.

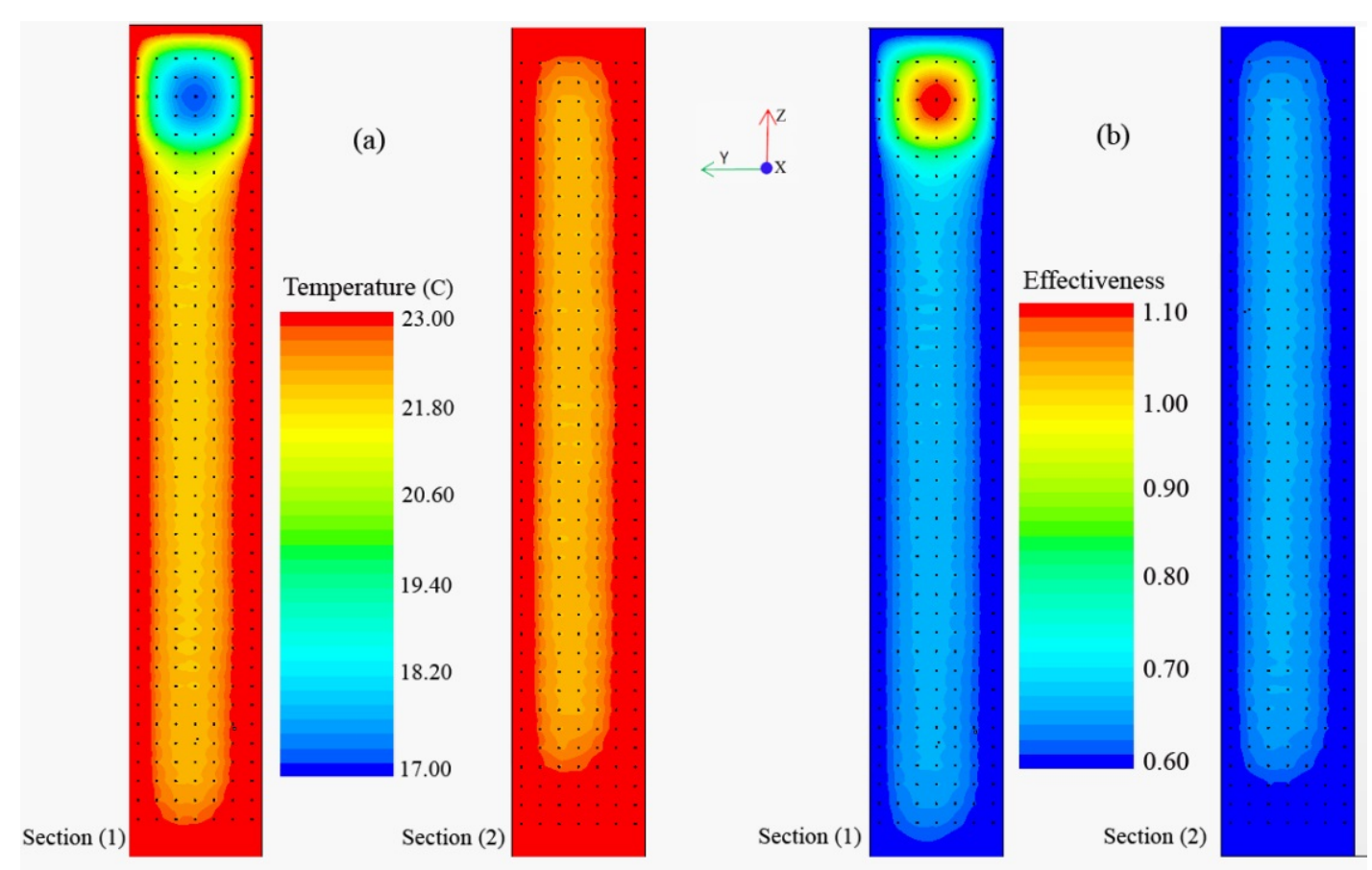

Fig. 10. Front view of: (a) Temperature distribution over the perforated plate, (b) Heat exchange effectiveness distribution over the perforated plate; Section (1): the upper part of the plate, Section (2): the lower part of the plate. 


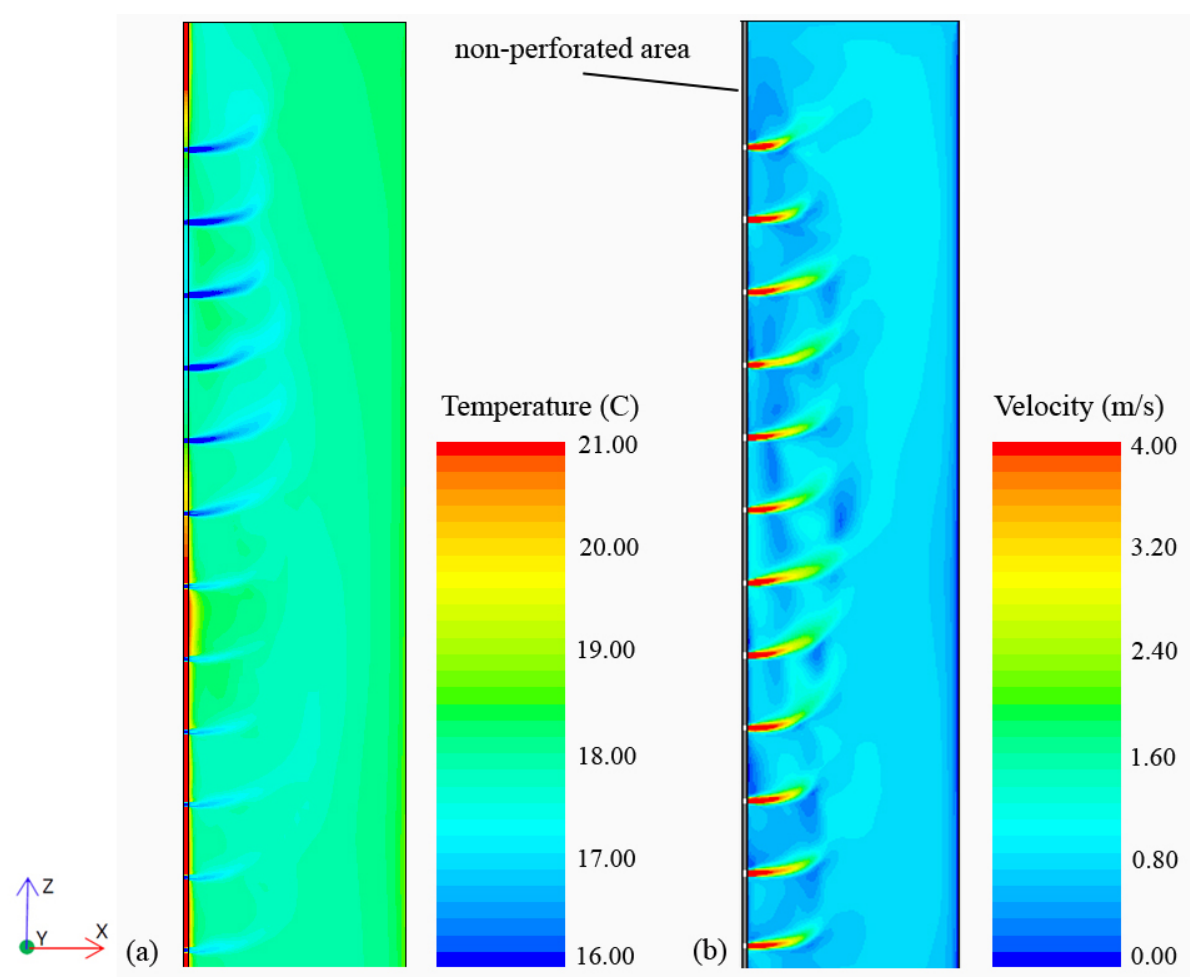

Fig. 11. Cross section of plenum showing; a)temperature and b)velocity distributions in upper part of plenum.

\subsection{Effects of Wind Angle}

Whilst the characteristics of the airflow approaching TSCs are believed to be important, the existing literature does not routinely consider the influence of wind angle on the thermal performance of TSC systems. Wind angle can affect the airflow distribution near the perforated plate, which in turn modifies the heat gain of the system and consequently the air temperature rise. Temperature rise refers to the ability of the system to raise the ambient temperature to a higher level at the outlet, and it is defined simply as the difference between the outlet temperature $\left(T_{\text {out }}\right)$ and ambient temperature $\left(T_{a m b}\right)$. Steady-state simulations have been performed to illustrate the parametric influence of wind angle, at different levels of suction ratio, on temperature rise and other performance parameters.

Table 2. Details of the case studied for Wind angle and Suction ratio effect

\begin{tabular}{|c|c|c|c|c|c|}
\hline Case number & $\begin{array}{c}\text { Wind angle }\left({ }^{\circ}\right) \\
\boldsymbol{\beta}\end{array}$ & $\begin{array}{c}\text { Suction ratio } \\
\left(\boldsymbol{V}_{\boldsymbol{s}} / \boldsymbol{U}_{\infty}\right)\end{array}$ & $\begin{array}{c}\text { Ambient Air } \\
\text { Temperature }\left({ }^{\circ} \mathrm{C}\right)\end{array}$ & $\begin{array}{l}\text { Wind speed }(\mathrm{m} / \mathrm{s}) \\
\boldsymbol{U}_{\infty}\end{array}$ & $\begin{array}{l}\text { Solar Radiation } \\
\qquad(\mathrm{w} / \mathrm{m} 2)\end{array}$ \\
\hline 1 & 0 & \multirow{4}{*}{0.004} & \multirow{16}{*}{10} & \multirow{16}{*}{3} & \multirow{16}{*}{600} \\
\hline 2 & 22.5 & & & & \\
\hline 3 & 45 & & & & \\
\hline 4 & 67.5 & & & & \\
\hline 5 & 0 & \multirow[t]{4}{*}{0.006} & & & \\
\hline 6 & 22.5 & & & & \\
\hline 7 & 45 & & & & \\
\hline 8 & 67.5 & & & & \\
\hline 9 & 0 & \multirow{4}{*}{0.008} & & & \\
\hline 10 & 22.5 & & & & \\
\hline 11 & 45 & & & & \\
\hline 12 & 67.5 & & & & \\
\hline 13 & 0 & \multirow{4}{*}{0.010} & & & \\
\hline 14 & 22.5 & & & & \\
\hline 15 & 45 & & & & \\
\hline 16 & 67.5 & & & & \\
\hline
\end{tabular}




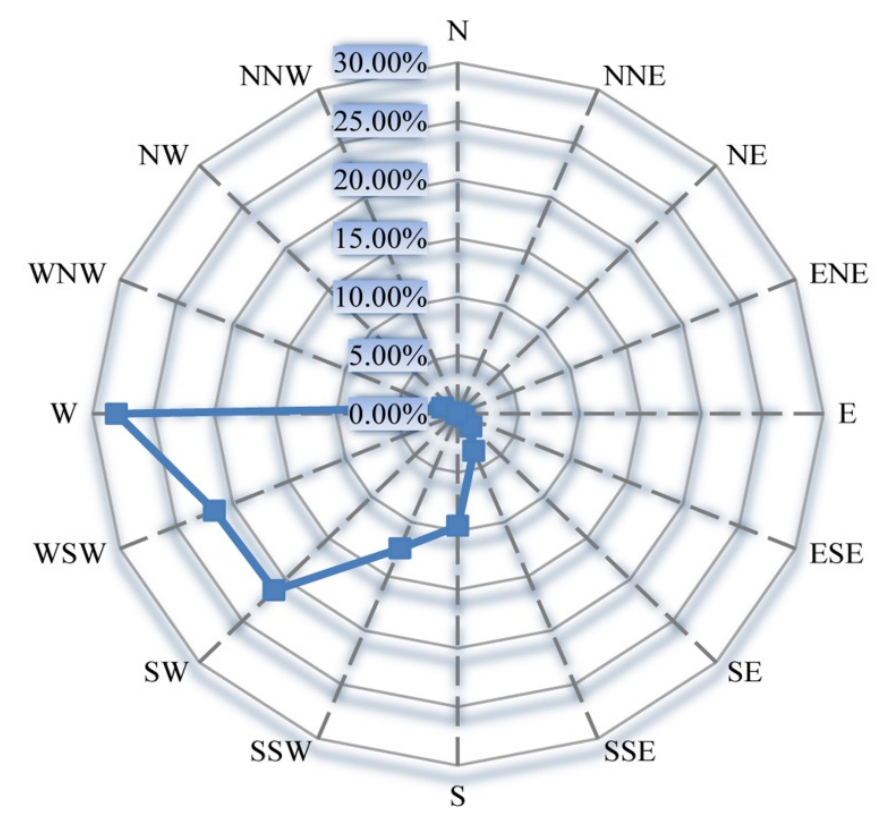

Fig. 12. The distribution of wind power by direction recorded at the trial site between $22^{\text {nd }}$ December 2011 to $4^{\text {th }}$ January 2012.

The data gathered from the weather station on the experimental site (Hall et al., 2013) suggests that the wind mostly blows from the west and the south west (Fig. 12) as might be expected in the south of England. For brevity, simulations have been carried out for the major range of wind angle as it has been detected on the trial site. Noting that the building is south-facing, the equivalent wind angle in the model would span mainly from $0^{\circ}$ to $67.5^{\circ}$; Fig. 13 provides a schematic view of wind flows approaching the TSC at different angles. The summary of the studied conditions is given in Table 2 .

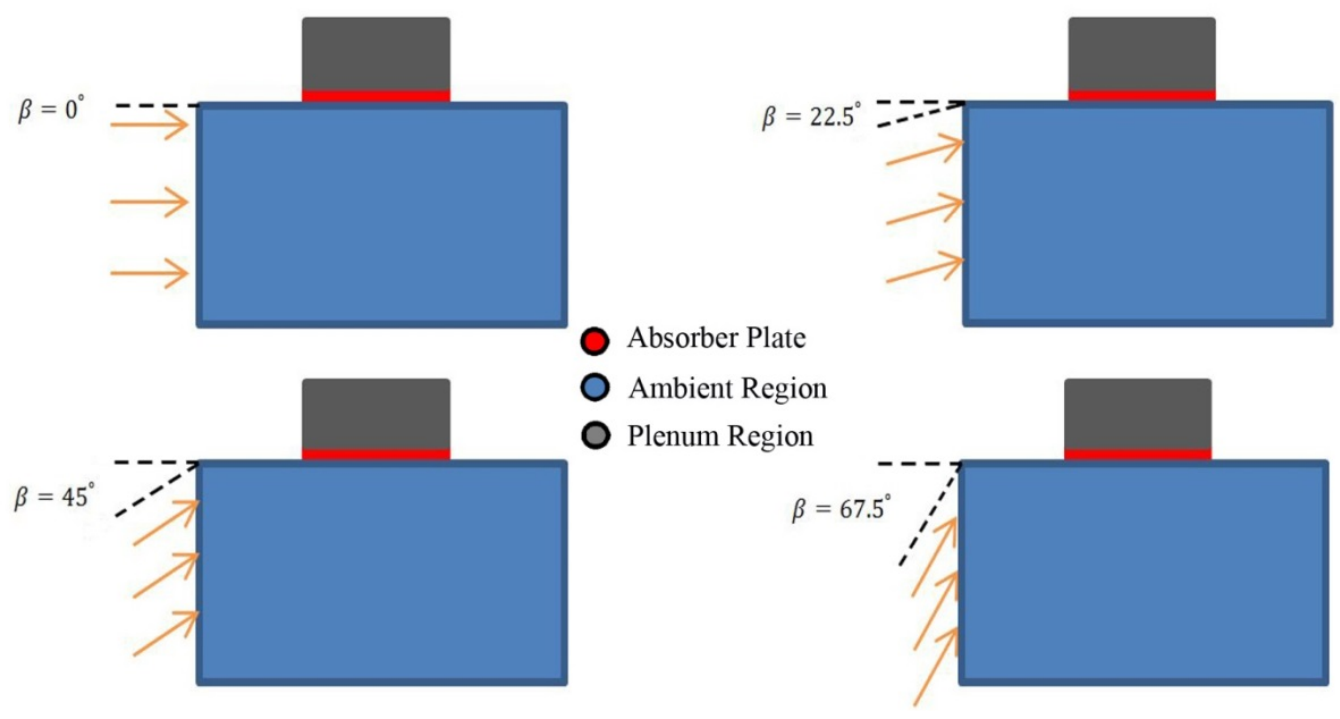

Fig. 13. Schematic of wind flow with different angles relative to the absorber plate.

Fig 14 shows temperature rise and absorber surface temperature as a function of wind angle, for different suction ratios. It can be seen that both 'temperature rise' and 'absorber surface temperature' reduce with increasing wind angle. The trend is similar for all cases, with increasing suction ratio leading consistently to lower surface and outlet temperatures. Surface temperature demonstrates an average decrease of $0.28^{\circ} \mathrm{C}$ per $10^{\circ}$ increase in wind angle. This suggests that increasing the angle of the approaching flow enhances the level of turbulence around the plate, leading to increased heat transfer from the plate to the external air flow. Similarly, the air temperature rise drops by approximately $0.19^{\circ} \mathrm{C}$ for every $10^{\circ}$ variation in wind angle with temperature 
reduction occurring most during the initial stages, indicating that the flow pattern does not change significantly after a given wind angle.

Inspection of the four cases shows the important influence of suction ratio on the operating temperatures of TSCs. The maximum effect of suction ratio occurs at $67.5^{\circ}$ where 'temperature rise' and 'surface temperature' drop significantly by about $58 \%$ and $28 \%$ for a change in suction ratios between 0.004 and 0.01 . This effect is less pronounced but still considerable at a wind angle of $0^{\circ}$ (36\% and $10 \%$, respectively). A similar pattern has been noted for the influence of suction ratio in the relevant literature (Biona et al., 2005; Leon and Kumar, 2007). As the simulations have been performed for constant wind speed $(3 \mathrm{~m} / \mathrm{s})$, higher suction ratio implies higher airflow velocity in the vicinity of the perforations, leading to lower temperature gradients on the surface of the absorber. Moreover, higher suction ratios increase the turbulent effect originating from a higher level of interaction between the suction and the approaching flow, which in turn tends to increase the heat transfer from the plate to the ambient air.
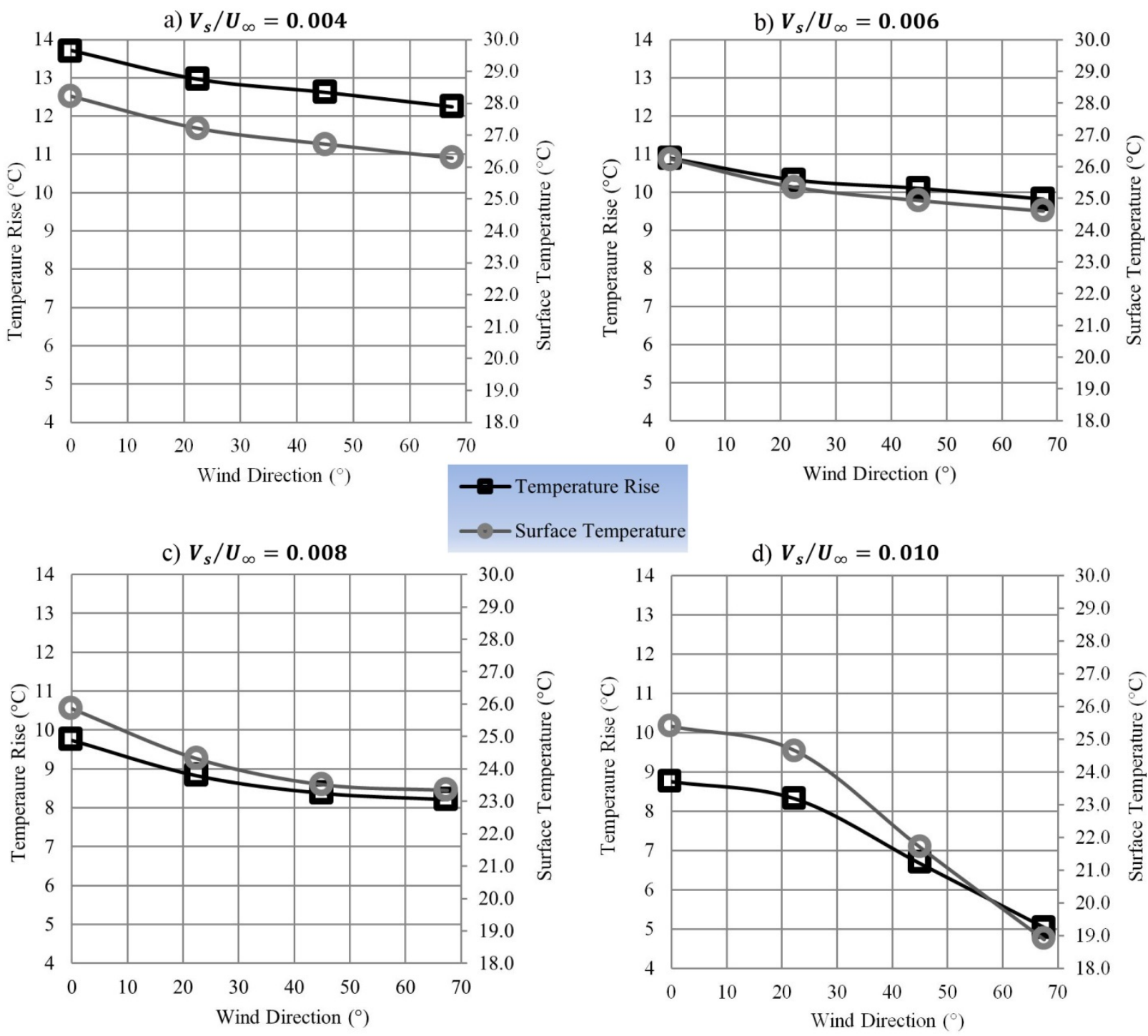

Fig 14. Impact of wind angle on temperature rise and absorber surface temperature for: (a) $V_{s} / U_{\infty}=0.004$, (b) $V_{s} / U_{\infty}=0.006$, (c) $V_{s} / U_{\infty}=0.008,(\mathrm{~d}) V_{s} / U_{\infty}=0.010$.

The predicted heat exchange effectiveness does not show significant changes with wind angle variation. When the suction ratio was varied between 0.004 and 0.01 , the average value of HEE dropped from 0.75 to 0.57 . For brevity, the variation of HEE with wind angle is not presented here. Wind angle affects the surface temperature and the respective outlet temperature almost equally, in such a way that no significant changes in HEE are detected. This implies that different wind angles do not have a major effect upon the heat transfer taking place within the perforations and the plenum where significant portion of heat transfer takes place 
(Gunnewiek et al., 1996; Van Decker et al., 2001). This also implies that the reduction in temperature rise would be mainly a consequence of that in absorber surface temperature.

\subsection{Effects of wind speed}

Steady-state CFD simulations were carried out to investigate the parametric influence of wind speed on temperature rise and absorber surface temperature. The results are plotted for different suction ratios in Fig. 15. The details of the cases studied are listed in Table 3.

Table 3. Details of the case studied for Wind speed and Suction ratio effect

\begin{tabular}{|c|c|c|c|c|c|}
\hline Case number & $\begin{array}{c}\text { Wind } \\
\text { Direction }\left(^{\circ}\right) \\
\boldsymbol{\beta}\end{array}$ & $\begin{array}{l}\text { Suction ratio } \\
\qquad\left(\boldsymbol{V}_{\boldsymbol{s}} / \boldsymbol{U}_{\infty}\right)\end{array}$ & $\begin{array}{c}\text { Ambient Air } \\
\text { Temperature } \\
\left({ }^{\circ} \mathrm{C}\right)\end{array}$ & $\begin{array}{l}\text { Wind speed }(\mathrm{m} / \mathrm{s}) \\
\boldsymbol{U}_{\infty}\end{array}$ & $\begin{array}{l}\text { Solar Radiation } \\
\qquad(\mathrm{w} / \mathrm{m} 2)\end{array}$ \\
\hline 1 & \multirow{16}{*}{0} & \multirow{4}{*}{0.004} & \multirow{16}{*}{10} & 1 & \multirow{16}{*}{600} \\
\hline 2 & & & & 2 & \\
\hline 3 & & & & 3 & \\
\hline 4 & & & & 4 & \\
\hline 5 & & \multirow{4}{*}{0.006} & & 1 & \\
\hline 6 & & & & 2 & \\
\hline 7 & & & & 3 & \\
\hline 8 & & & & 4 & \\
\hline 9 & & \multirow{4}{*}{0.008} & & 1 & \\
\hline 10 & & & & 2 & \\
\hline 11 & & & & 3 & \\
\hline 12 & & & & 4 & \\
\hline 13 & & \multirow{4}{*}{0.010} & & 1 & \\
\hline 14 & & & & 2 & \\
\hline 15 & & & & 3 & \\
\hline 16 & & & & 4 & \\
\hline
\end{tabular}

As shown in Fig. 15, the system operating temperature tends to reduce at increasing suction ratio and wind speed. Changing wind speed from 1 to $4 \mathrm{~m} / \mathrm{s}$ leads to a reduction in the air temperature rise and the surface temperature by an average of $57 \%$ and $29 \%$ respectively for different suction ratios. However, when operating at lower wind speed, the system experiences a wider range of temperature variation as suction ratio increases from 0.004 to 0.01 . At $4 \mathrm{~m} / \mathrm{s}$ wind speed, the air temperature rise is predicted to vary about $10.5{ }^{\circ} \mathrm{C}$ against suction ratio, whereas at $1 \mathrm{~m} / \mathrm{s}$ wind speed it shows a variation of about $14.5^{\circ} \mathrm{C}$. A similar trend is apparent for the surface temperature. This effect indicates that the higher levels of suction ratio lessen the effect of wind speed on the system's operating temperature. Whilst this suggests that a lower suction ratio should be applied to the system to reach specific levels of temperature rise, this increases the risk of reverse flow over the absorber plate. In other words, although low suction ratio values would give a better thermal performance, the airflow would be partially reversed which compromises the systems' heat gain by taking the collected energy away from the absorber through the perforations (Gunnewiek, 2002). This represents an important design parameter. . 
a) $\boldsymbol{V}_{s} / \boldsymbol{U}_{\infty}=\mathbf{0 . 0 0 4}$

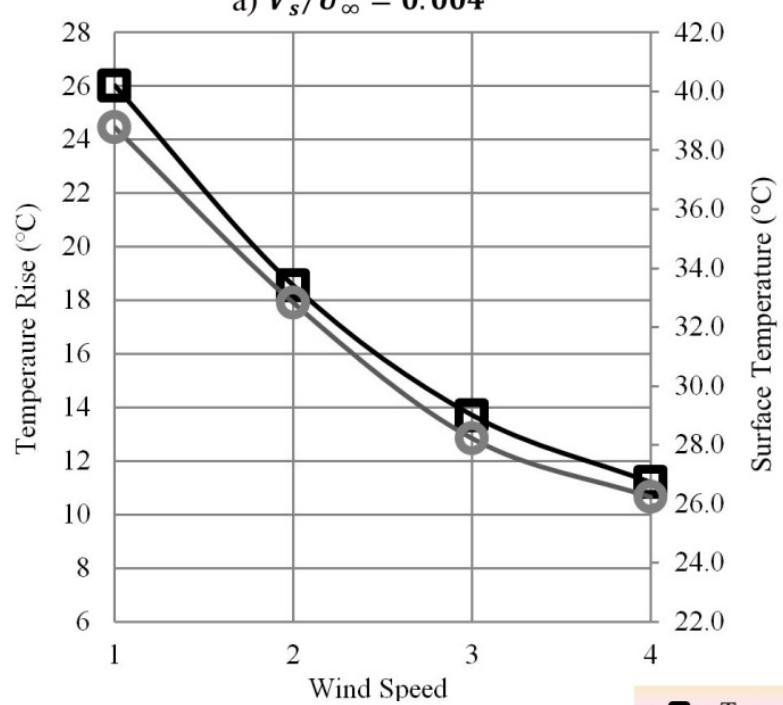

b) $V_{s} / U_{\infty}=0.006$

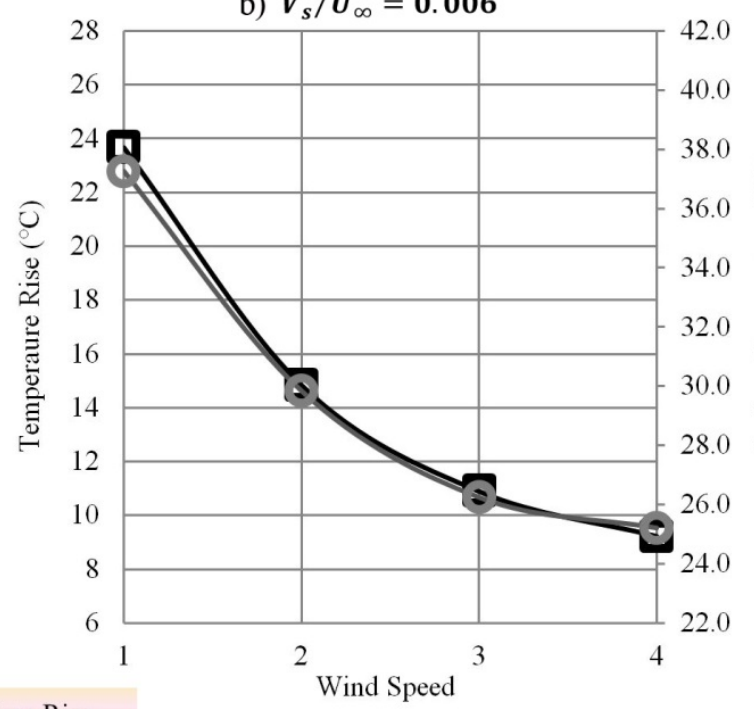

d) $V_{s} / U_{\infty}=\mathbf{0 . 0 1 0}$

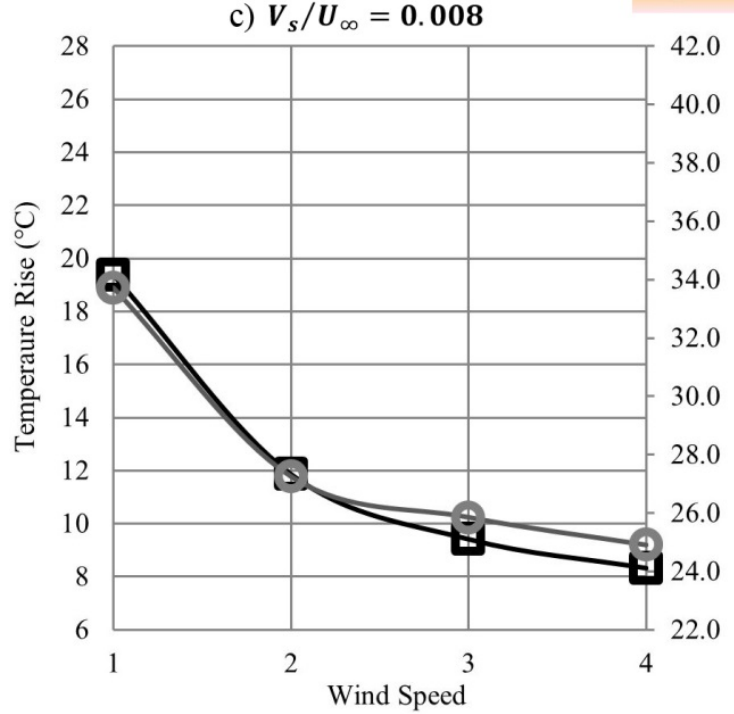

Surface Temperature

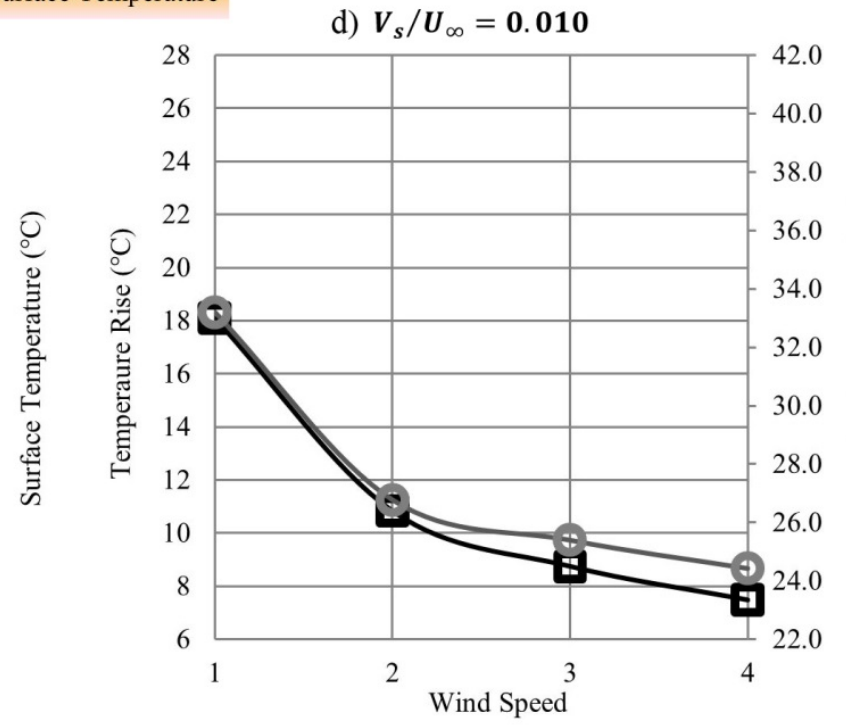

42.0

40.0

Fig. 15. Impact of wind speed on temperature rise and absorber surface temperature for: (a) $V_{s} / U_{\infty}=0.004$, b) $V_{s} / U_{\infty}=0.006$, c) $V_{s} / U_{\infty}=0.008$, d) $V_{s} / U_{\infty}=0.010$, with constant wind angle of $\beta=0^{\circ}$.

As well as influencing both the temperature rise and surface temperature, wind speed has a significant effect upon the heat exchange effectiveness, due to major alterations of the heat transfer processes within the plenum. The parametric variation of HEE as a function of wind speed, for different levels of suction ratio is presented in Fig. 16. HEE decreases considerably with both increasing wind speed and increasing suction ratio, over a wide range between 0.9 and 0.5 . Changing suction ratio from 0.004 to 0.01 causes HEE to reduce on average by $26 \%$. When the suction ratio is 0.01 , increasing the wind speed between 1 and $4 \mathrm{~m} / \mathrm{s}$ changes HEE by about $50 \%$; when the suction ratio decreases to 0.004 , the same variation in wind speed causes a change in HEE of only $33 \%$. The highest value of HEE is predicted at the lowest levels of wind speed and suction ratio investigated. Although the system thermal performance is predicted to be significantly greater at these conditions, reverse flow becomes a major risk. 
a) $V_{s} / U_{\infty}=\mathbf{0 . 0 0 4}$

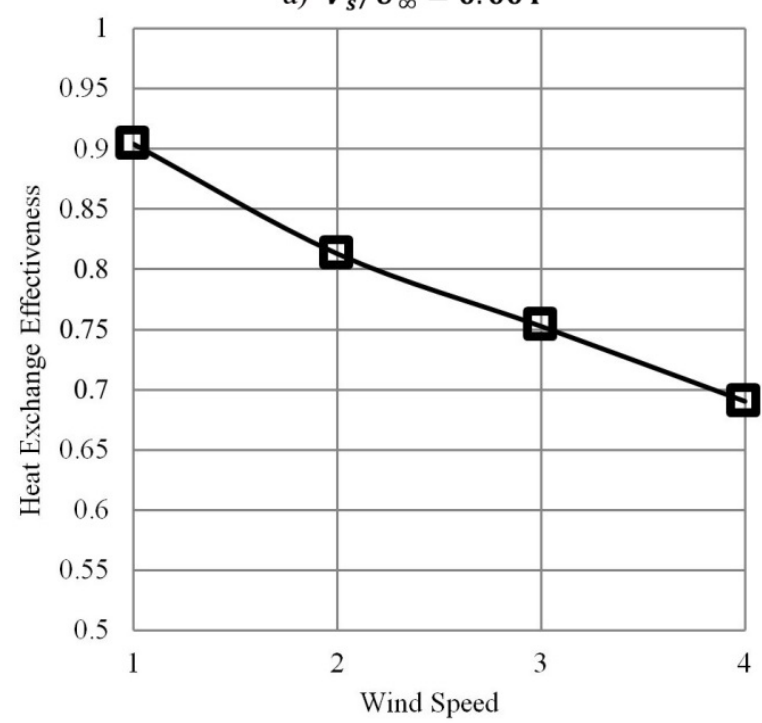

c) $V_{s} / U_{\infty}=0.008$

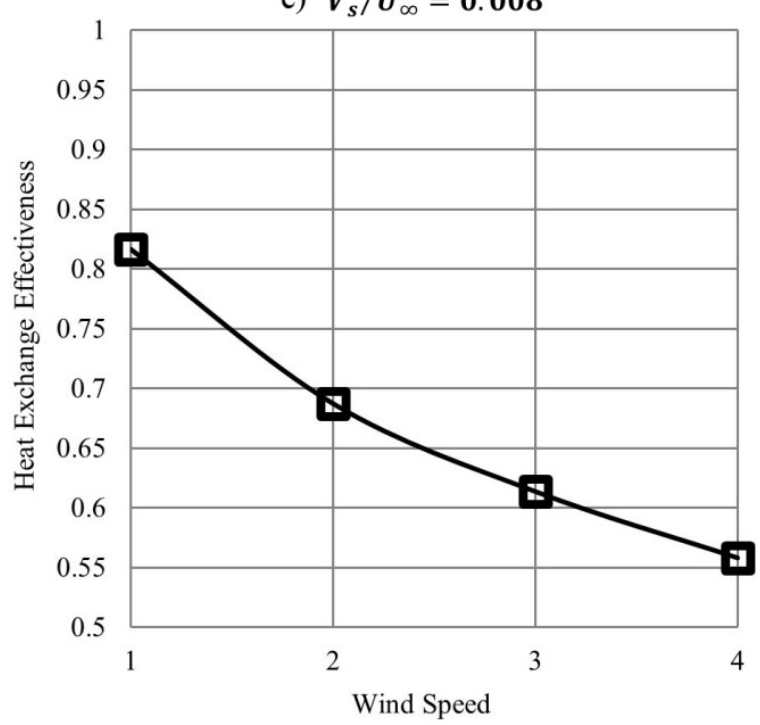

b) $V_{s} / U_{\infty}=0.006$

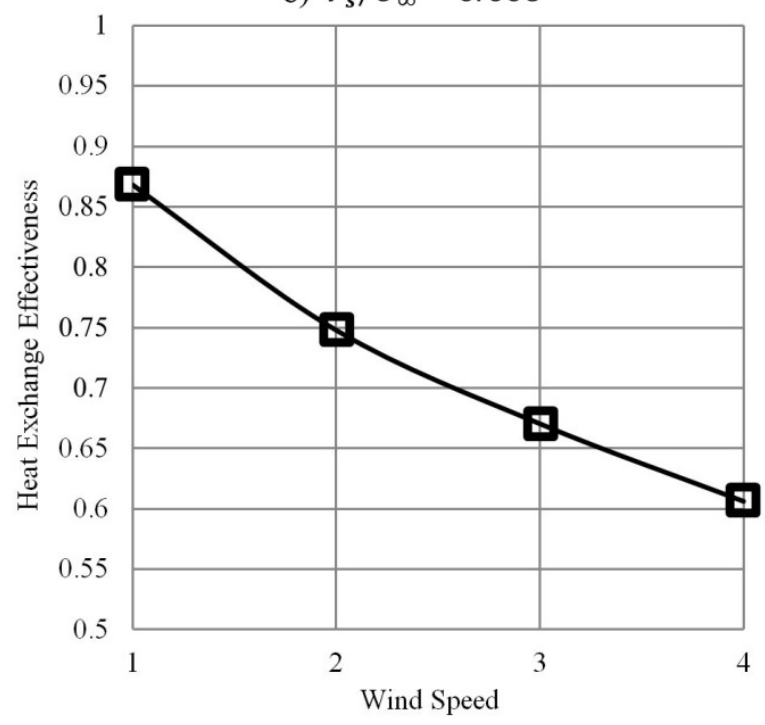

d) $V_{s} / U_{\infty}=\mathbf{0 . 0 1 0}$

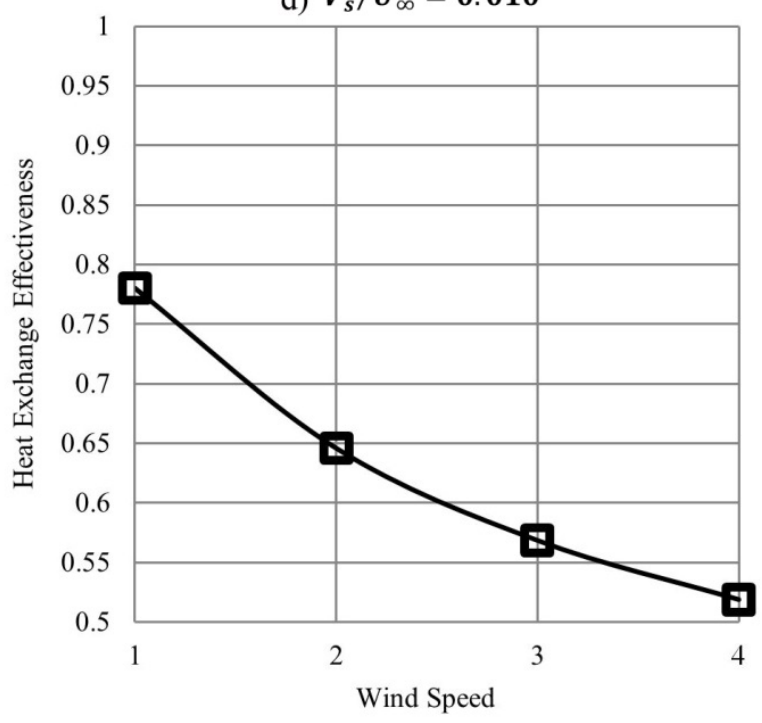

Fig. 16. Impact of suction ratio on heat exchange effectiveness for: (a) $V_{s} / U_{\infty}=0.004$, b) $V_{s} / U_{\infty}=0.006$, c) $V_{s} / U_{\infty}=0.008$, d) $V_{s} / U_{\infty}=0.010$, with constant wind angle of $\beta=0^{\circ}$.

\subsection{Effects of solar radiation}

Solar radiation drives the absorber plate heating process and exploring its influence using CFD simulations is particularly useful for practical applications of TSC systems. Thus, four realistic values of solar radiation intensity have been adopted from the available recorded data (Hall et al., 2013) to model the system thermal response, in combination with different wind angles, at a fixed wind speed of $3 \mathrm{~m} / \mathrm{s}$, suction ratio of 0.008 and ambient air temperature of $10^{\circ} \mathrm{C}$. The results of the parametric study are presented in Fig. 17. 
a) $\boldsymbol{\beta}=\mathbf{0}^{\circ}$

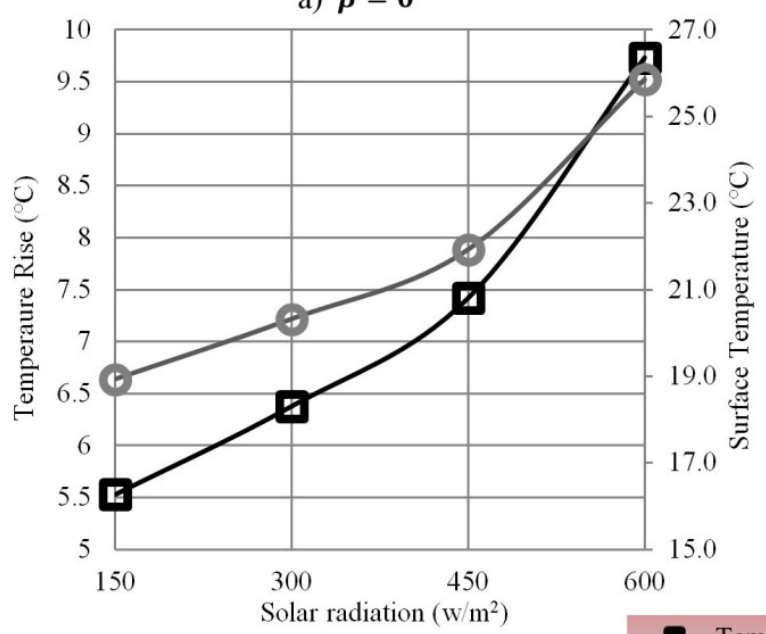

b) $\beta=22.5^{\circ}$

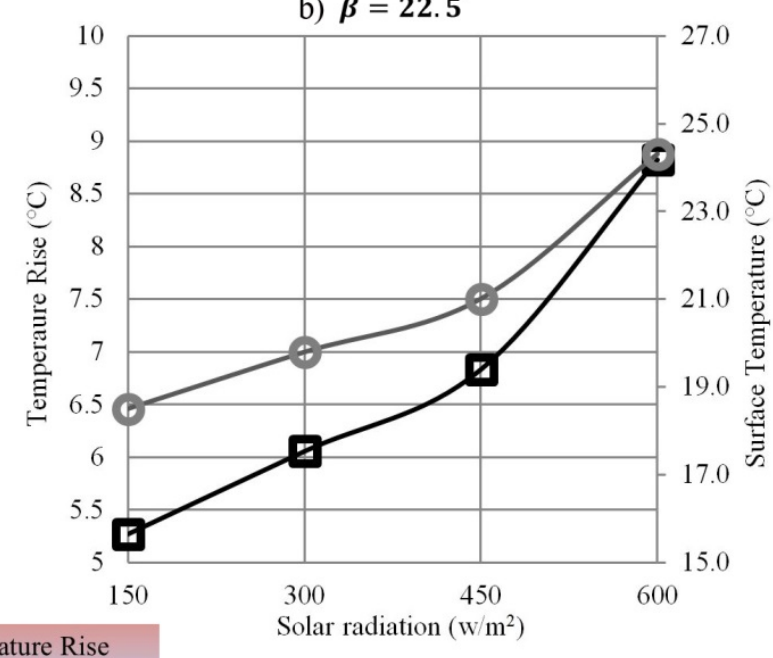

c) $\beta=45^{\circ}$

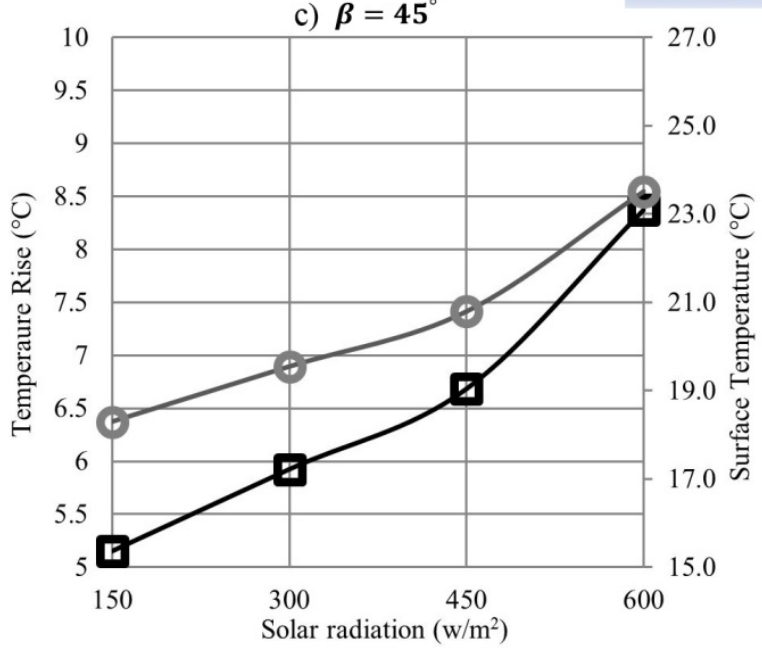

d) $\beta=67.5$

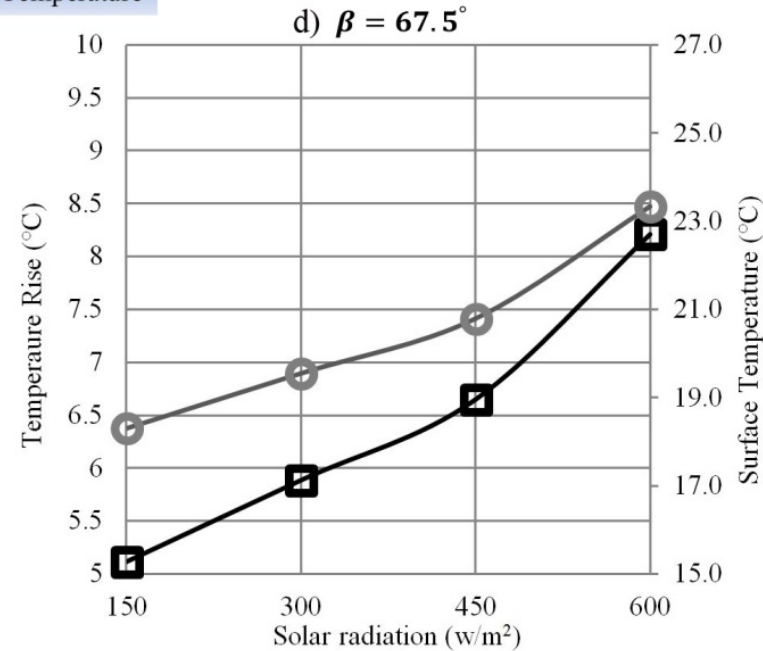

Fig. 17. Impact of solar radiation on temperature rise and absorber surface temperature for: (a) $\beta=0^{\circ}$, (b) $\beta=22.5^{\circ}$, (c) $\beta=45^{\circ}$, (d) $\beta=67.5^{\circ}$.

As expected, both 'surface temperature' and air 'temperature rise' increase with increasing solar radiation. The size of increase is moderated by a greater wind angle. Increasing solar radiation from 150 to $600 \mathrm{~W} / \mathrm{m}^{2}$ raises the surface temperature by about $33 \%$ at $\beta=0^{\circ}$, allowing the TSC to operate at higher temperatures. This effect is more pronounced on the temperature rise, delivering a $70 \%$ enhancement for the same solar radiation change. At the highest wind angle $\left(\beta=67.5^{\circ}\right)$, the temperature rise still grows with solar radiation, but by less (60\%). These results could help researchers and designers investigating novel TSC systems, as they suggest wind angle must be considered if system performance is to be maintained in varying external conditions. However, as reported in section 3.2, increases in the angle of the wind angle $(\beta)$ have a diminishing influence on temperature rise when other variables are kept constant. For instance, at constant solar radiation of $600 \mathrm{~W} / \mathrm{m}^{2}$, changing wind angle from 0 to $22.5^{\circ}$ gives a $1.5^{\circ} \mathrm{C}$ drop in surface temperature, whereas this reduces to $0.8^{\circ} \mathrm{C}$ when the wind angle is increased from 22.5 to $45^{\circ}$. The predicted values of effectiveness show limited variation when the solar radiation is increased between 150 and $600 \mathrm{~W} / \mathrm{m}^{2}$; the average HEE value was 0.618 . For brevity, HEE results are not presented here.

\subsection{Effects of 'Time of the day'}

The absorber plate receives solar radiation at different angles depending on time and sun angle. Star-CCM+ CFD software has the 'Solar Load' sub-model giving the ability to investigate system performance at prescribed times. The simulations for this study are for $22^{\text {nd }}$ of December (using the location indicated in the section 'Background'). Five different times were considered, whereas other variables were kept constant: solar radiation, $600 \mathrm{~W} / \mathrm{m}^{2}$; wind angle $(\beta), 0^{\circ}$; wind speed, $3 \mathrm{~m} / \mathrm{s}$; and suction ratio, 0.01 . The results are displayed in 
Fig. 18.
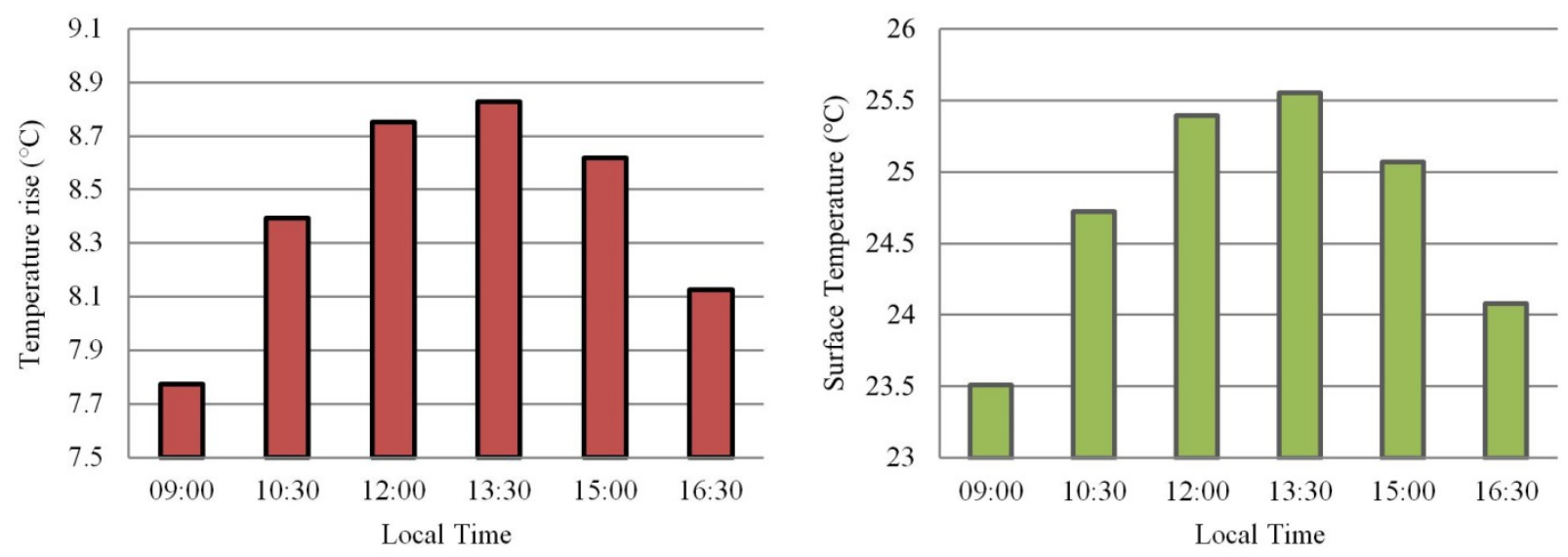

Fig. 18. Impact of day time on temperature rise and absorber surface temperature.

Both temperature rise and surface temperature increase from the morning until early afternoon before reducing later in the afternoon when the sun drops. Noting that the simulations have been performed for constant solar intensity, the trend would be different at early mornings and late afternoons when the solar intensity is significantly less than at mid-day. This implies that TSCs are able to deliver a reasonable air temperature into buildings around noon although heat is mostly required in the early morning and late afternoon/evening periods. Heat storage systems are likely therefore to be highly advantageous if TSCs are to be fully optimised against the heating needs of common building types and normal occupancy patterns.

\section{Conclusion}

TSCs have significant and quantifiable potential to reduce the present reliance on fossil fuels for heating buildings, and therefore to play an important role in meeting UK and international carbon reduction targets. The relative technical simplicity of systems is highly desirable as many other zero and low emission technologies have capital and in service costs that are prohibitive to their wider use. This work informs understanding of key aspects of the underlying building physics and for the first time provides a suitably accurate method of modelling systems such that performance can be optimised. Such optimisation is key both to increasing the periods of useful operation of systems (such that they are active diurnally and seasonally for the longest feasible periods), and in raising the temperature of air delivered by systems which is likely to prove essential if effective thermal storage systems are to be developed to work in conjunction with TSCs. It is therefore intended to facilitate future high quality and effective systems optimisation research, and more intensive use of the approach.

This study has involved the development of a high-resolution, 3-dimensional, steady, RANS CFD approach to model cassette-panel TSC systems. Multi-block meshing has been used to capture the multi-scale air flow behaviour which establishes in the various regions of the physical system. Angle of wind angle and the actual position of the sun have been taken into account in the simulations.

Experimental data from tests conducted at Oxford Brookes University have been used to validate the accuracy of the CFD model. Parametric studies were then carried out in relation to a variety of operating regimes and climates. Key finding include:

- Air flow is almost parallel to the absorber external surface irrespective of the angle of approach.

- The air 'temperature rise' (the difference between the outlet temperature and ambient temperature) and the 'surface temperature' of the absorber plate, both reduce as the wind angle increases relative to the absorber plate. This impact has been shown to be $0.28^{\circ} \mathrm{C}$ per 10 degree variation in wind angle for surface temperature and $0.19{ }^{\circ} \mathrm{C}$ per 10 degree variation in wind angle for temperature rise.

- Similarly, and in agreement with previous research (section 3.3), increasing the suction ratio decreases both air 'temperature rise' and the 'surface temperature' of the absorber plate. This effect increases through the analysed range of wind angles from $0-67.5^{\circ}$. Further research may therefore be 
appropriate to develop systems that have reduced sensitivity to wind angle.

- Simulations using different suction ratios reveal that wind speeds ranging from 1 to $4 \mathrm{~m} / \mathrm{s}$ reduce both 'temperature rise' and 'surface temperature'. The impact of suction ratio increases at lower wind speeds.

- Increasing both suction ratio and wind speed lead to a reduction in Heat Exchange Effectiveness. Wind speed has a greater effect on effectiveness at higher suction ratios. The studied cases have demonstrated that effectiveness reaches its highest value when the system operates at the lowest suction ratio with the lowest wind speed. This condition does however generate risk of reverse flow over the absorber plate.

- Wind angle influences the impact of solar radiation on the operating temperatures of TSCs. Increasing solar radiation from 150 to $600 \mathrm{~W} / \mathrm{m}^{2}$ at $\beta=0^{\circ}$ (parallel flow) is $10 \%$ more effective than that at $\beta=$ $67.5^{\circ}$.

- Wind angle and solar radiation have little effect on Heat Change Effectiveness indicating that they are relatively insignificant to the amount of heat transfer that occurs within the perforations and in the plenum; outlet air temperature only increases in accordance with absorber plate 'surface temperature'.

- TSCs deliver different operating temperatures dependent on time of day. Since the position of the sun moves the exposure of the absorber plate to the sun varies, with consequent obvious changes in the received solar radiation and heat gains. The characterisation of sun movement is notably lacking in previous modelling but in the developed approach it is properly represented.

The observed behaviour of a Transpired Solar Collector as shown in these validated parametric modelling studies can inform the development and deployment of the technology. In particular, performance characteristics can be evaluated and used to improve aspects of TSC design and operation. For example, control of fan speed can be introduced in tandem with wind speed and direction monitoring to achieve the most beneficial suction ratio for the conditions encountered, and thermal storage systems can be modelled and investigated using realistic solar availability.

Future research using this CFD tool will investigate the development of enhanced TSCs that can be optimised both in terms of efficiency (and hence size) and for performance under real conditions, widening the potential for application on buildings in the UK, Europe and internationally in climates where there is both heating demand and reasonable availability of solar radiation.

\section{References}

Abulkhair, H., Collins, M., 2010. Investigation of wind heat loss from unglazed transpired solar collectors with corrugation. In: 5th Annual International Green Energy Conference, Waterloo, Ontario, June 1-3, 2010.

Arulanandam, S.J., Hollands, K.G.T., Brundrett, E., 1999. A CFD heat transfer analysis of the transpired solar collector under no-wind conditions. Solar Energy 67 (1), 93-100

Athienitis, A.K., Bambara, J., O’Neill, B., Faille, J., 2011. A prototype photovoltaic/thermal system integrated with transpired collector. Solar Energy 85, 139-153.

Biona, M., Culaba, A., Serafica, E., Mundo DR., 2005. Performance curve generation of an unglazed transpired collector for solar drying applications. In: Proceedings of World Renewable Energy Regional Conference.

Collins, M., Abulkhair, H., 2014. An evaluation of heat transfer and effectiveness for unglazed transpired solar air heaters. Solar Energy 99, 231-245.

Commission of the European Communities, 2014. A policy framework for climate and energy in the period from 2020 to 2030 , COM (2014) 15 final. Brussels.

Committee on Climate Change, 2014. Meeting Carbon Budgets - 2014 Progress Report to Parliament. https:/www.theccc.org.uk/wpcontent/uploads/2014/07/CCC-Progress-Report-2014_web_2.pdf.

Dutton, R.A., 1958. The effects of distributed suction on the development of turbulent boundary layers. Aeronautical Research Council Technical Report, R\&M No. 3155, London, England.

Dymond, C, Kutscher C. Development of a flow distribution and design model for transpired solar collectors, 1997. Solar Energy.;60(5):291-300.

Gawlik, K.M., 1993. A numerical and experimental investigation of heat transfer issues in the practical utilization of unglazed, transpired solar air heaters. Ph.D. Thesis, Department of Civil, Environmental, and Architectural, University of Colorado, Colorado, USA.

Gawlik, K.M., Christensen C, Kutscher C., 2005. A Numerical and Experimental Investigation of Low-conductivity Unglazed, Transpired Solar Air Heaters. ASME Journal of Solar Energy Engineering.127 (1),153-155. 
Golneshan, A., 1994. Forced convection heat transfer from low porosity slotted transpired plates. Ph. D. Thesis, Department of Mechanical Engineering, University of Waterloo.

Gunnewiek, L., Brundrett, E., Hollands, K., 1996. Flow distribution in unglazed transpired plate solar air heaters of large area. Solar Energy 58:227-237.

Gunnewiek, L., Hollands, K., Brundrett E., 2002. Effect of wind on flow distribution in unglazed transpired plate collectors. Solar Energy $72,317-325$

Hall, R., Kendrick C., Lawson, M.R., 2013. Development of a cassette-panel transpired solar collector. ICE Energy, 16, 32-41.

Hollick, J., 1994. Unglazed solar wall air heaters. Renewable Energy 5, 415-421.

Kutscher, C.F., 1992. An investigation of heat transfer for air flow through low porosity perforated plates. Ph.D. Thesis, Department of Mechanical Engineering, University of Colorado at Boulder, Colorado, USA.

Kutscher, C.F., Christensen, C., Barker, G., 1993. Unglazed transpired solar collectors: heat loss theory. ASME Journal of Solar Engineering 115, 182-188.

Kutscher, C.F., 1994. Heat exchanger effectiveness and pressure drop for air flow through perforated plates with and without crosswind. Journal of Heat Transfer 116, 391-399.

Leon, M., Kumar S., 2007. Mathematical modeling and thermal performance analysis of unglazed transpired solar collectors. Solar Energy $81,62-75$

Li, S., Karava, P., Savory, E., Lin, W., 2013. Airflow and thermal analysis of flat and corrugated unglazed transpired solar collectors. Solar Energy 91, 297-315.

Li, S., Karava, P., Currie, S., Lin, W., Savory, E., 2014. Energy modeling of photovoltaic thermal systems with corrugated unglazed transpired solar collectors - Part 1: Model development and validation. Solar Energy 102, 282-296.

Moffat, R.J., Kays, W.M., 1984. A review of turbulent-boundary-layer research at Stanford, 1958-1983. Advances in Heat Transfer 16, 242

363.

Schlichting, H., 1979. Boundary Layer Theory, seventh ed. McGraw-Hill, Book Co., New York, pp. $392-393$.

STAR-CCM+® CD-adapco, 2014. STAR-CCM+9.04.009 USER GUIDE.

Tajdaran, S., Bonatesta, F., Ogden, R., Kendrick, C., 2015. Use of CFD modelling for transpired solar collectors and associated characterization of multi-scale airflow and heat transfer mechanisms. In: 6th International Building Physics Conference, Turin, June 1417,2015 .

Van Decker, G.W.E., Hollands, K.G.T., Brunger, A.P., 2001. Heat-exchange relations for unglazed transpired solar collectors with circular holes on a square or triangular pitch. Solar Energy 71, 33-45. 